\title{
Software Quality Assurance Documentation for the Release of NUFT 2.0 for HP Platforms
}

\author{
Michael W. Fernandez \\ Gary L. Johnson \\ Gary G. Preckshot
}

August 28, 1998

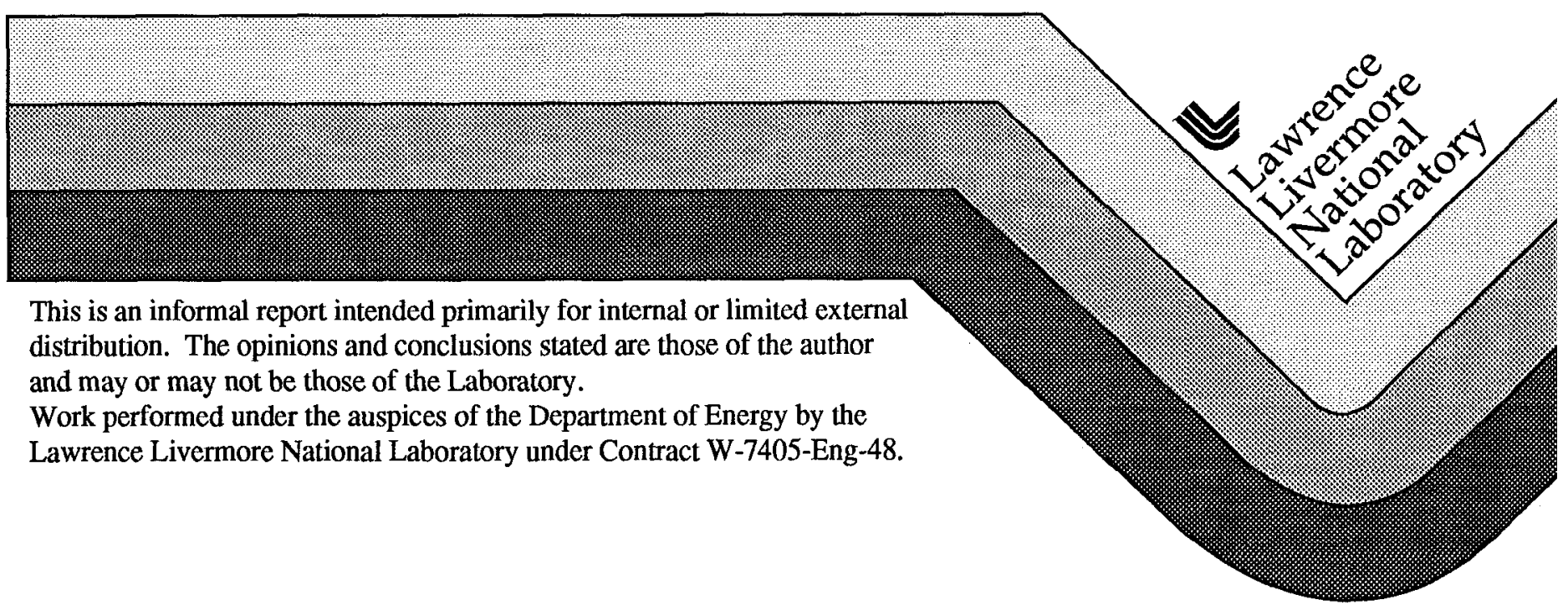




\section{DISCLAIMER}

This document was prepared as an account of work sponsored by an agency of the United States Government. Neither the United States Government nor the University of California nor any of their employees, makes any warranty, express or implied, or assumes any legal liability or responsibility for the accuracy, completeness, or usefulness of any information, apparatus, product, or process disclosed, or represents that its use would not infringe privately owned rights. Reference herein to any specific commercial product, process, or service by trade name, trademark, manufacturer, or otherwise, does not necessarily constitute or imply its endorsement, recommendation, or favoring by the United States Government or the University of California. The views and opinions of authors expressed herein do not necessarily state or reflect those of the United States Government or the University of California, and shall not be used for advertising or product endorsement purposes.

This report has been reproduced directly from the best available copy.

Available to DOE and DOE contractors from the Office of Scientific and Technical Information P.O. Box 62, Oak Ridge, TN 37831

Prices available from (615) 576-8401, FTS 626-8401

Available to the public from the

National Technical Information Service

U.S. Department of Commerce

5285 Port Royal Rd.

Springfield, VA 22161 
Software Quality Assurance Documentation for the Release of NUFT 2.0 for HP platforms

Michael W. Fernandez

Gary L. Johnson

August 28, 1998 
ISP-NF-13

Revision 1

\title{
LLNL-YMP
}

\section{Volume 1. Individual Software Plan for the Qualification of NUFT Version 2.0}

\author{
G. Gary Preckshot
}

April 14, 1998 


\title{
LLNL-YMP
}

\section{Individual Software Plan for the Qualification of NUFT \\ Version 2.0}

\author{
G. Gary Preckshot
}

April 14, 1998

G.Gary Preckshot

Michael Fernandez

Date

Technical Area Leader

James Blink

CRWMS LLNL Manager 


\section{Introduction}

This document is the Individual Software Plan (ISP) for version 2.0 of the Non-isothermal Unsaturated-saturated Flow and Transport (NUFI) analysis computer program. This document addresses the applicable requirements of LLNL YMP procedure 033-YMP-QP 3.2, Section 4.2.1.1.

\subsection{Purpose}

The purpose of this ISP is to plan and organize the activities required to certify the NUFT code for quality affecting work involving problems that include cross drift analysis of the Yucca Mountain Repository facility. NUFT is software for application to the solution of a class of coupled mass and heat transport problems in porous geologic media including Yucca Mountain Repository Cross Drift Problem (YMRCDP-also known as the Enhanced Characterization of the Repository Block (ECRB)). Solution of this class of problems requires a suite of multiphase, multi-component models for numerical solution of nonisothermal flow and transport in porous media with applications to subsurface contaminant transport problems.

\subsection{Product Identification}

NUFT is a suite of multiphase, multi-component models for numerical solution of nonisothermal flow and transport in porous media, with application to subsurface contaminant transport problems, and in particular, to the hydrology in and about the Yucca Mountain Repository Site. NUFT is acquired software, as defined by 033-YMP-QP 3.2, and a preliminary baseline of source code, electronic documentation, and paper documentation has been established as required by 033-YMP-QP 3.2, Section 4.1. NUFT runs on Sun Unix platforms, Solaris operating system version 5.5 and HP-UX with operating system version 10.20. The product to be qualified under this ISP is the version running on HPUX. The HP version will be labeled Version 2.0h. The " $\mathrm{h}$ " is included to distinguish the HP version from possible future versions qualified for Sun or other platforms.

\subsection{Scope}

The scope of the plans and procedures outlined in this ISP is limited to the effort required to qualify NUFT for the class of problems identified in section 1.1 above, to meet the applicable requirements of 033-YMP-QP 3.2, and to establish a Version 2.0 baseline for subsequent qualifications of NUFT for additional problems or for use on additional platforms. The detailed requirements applicable to the class of problems for which this release is applicable will be defined in the NUFT 2.0 Requirements Document.

The scope of this ISP is limited to NUFT. Auxiliary software such as the post-processing tool XTOOL, YMESH, and RADPRO, which are often used in conjunction with NUFT, will be addressed separately as needed.

Version 2.0 is the first quality controlled release for the NUFT software. Additional releases are anticipated. NUFT Version 2.0 is "acquired software," as defined by 033 YMP-QP 3.2. Version 1.0 was released in February 1998, but that certification is being withdrawn based upon the quality assurance surveillance findings described in LLNL-98D-065.

\section{Organization}

LLNL's YMP has established a multidisciplinary team of software professionals and domain experts, shown in Sections 2.2 and 2.3. 


\subsection{Product Life Cycle}

The NUFT life cycle consists of an initial iteration of the following phases, which will be followed by future iterations of phases as required by development, change, or qualification purpose.

- Requirements phase

- Acquisition phase (not applicable)

- Verification and validation phase

- Installation and support phase

Additional phases (as part of a spiral model of life cycle progression) will be defined by subsequent ISPs or revisions to this ISP..

\subsection{Project Definition and Organization}

The NUFT project will be accomplished by six groups under the direction of the code sponsor or at the code sponsor's disposal by YMP policy. The V\&V team will perform verification and validation that NUFT meets the requirements for Version 2.0. The SCM coordinator will maintain control of NUFT code and impose a change control discipline on persons or organizations seeking to modify NUFT code. The CRWMS LLNL manager will be responsible for ensuring that appropriate resources are assigned to accomplish impact analyses required for defect resolution in a timely manner. The independent technical reviewer(s) will provide independent technical oversight of the entire process through review of produced documents. The QA records system will provide records retention, tracking, and retrieval for quality assurance records generated during the project. All participants will report to, or provide work products defined in this ISP to the code sponsor.

\subsection{Responsibilities}

\begin{tabular}{|l|l|l|}
\hline Participant & Person or Entity & Responsible For: \\
\hline Code Sponsor & John Nitao & $\begin{array}{l}\text { Overall responsibility for } \\
\text { ensuring procedures in 033- } \\
\text { YMP-QP 3.2 are followed } \\
\text { and life cycle coordination }\end{array}$ \\
\hline $\begin{array}{l}\text { Technical Area Leader } \\
\text { for post certification } \\
\text { activities) }\end{array}$ & M. W. Fernandez & $\begin{array}{l}\text { Overall responsibility for } \\
\text { management of qualification } \\
\text { activities }\end{array}$ \\
\hline $\begin{array}{l}\text { Technical Area Leader } \\
\text { for post certification } \\
\text { activities) }\end{array}$ & Wunan Lin & $\begin{array}{l}\text { Overall responsibility for } \\
\text { management of post } \\
\text { certification activities. }\end{array}$ \\
\hline $\begin{array}{l}\text { V\&VTeam Leader } \\
\text { SCM Coordinator }\end{array}$ & $\begin{array}{l}\text { Responsible for definition } \\
\text { and execution of the V\&V } \\
\text { Plan }\end{array}$ \\
\hline Gary L. Johnson & $\begin{array}{l}\text { Responsible for Software } \\
\text { Configuration Management } \\
\text { (SCM) functions and defect } \\
\text { report tracking defined under } \\
\text { 033-YMP-QP 3.2 }\end{array}$ \\
\hline
\end{tabular}




\begin{tabular}{|l|l|l|}
\hline Participant & Person or Entity & Responsible For: \\
\hline CRWMS LLNL Manager & James A. Blink & $\begin{array}{l}\text { Responsible for approval of } \\
\text { this ISP and for ensuring } \\
\text { defect resolution results are } \\
\text { used to check previous uses } \\
\text { of the certified code. }\end{array}$ \\
\hline $\begin{array}{l}\text { Independent Technical } \\
\text { Reviewer }\end{array}$ & Charles Carrigan & $\begin{array}{l}\text { Responsible for review of } \\
\text { the technical documents } \\
\text { produced. }\end{array}$ \\
\hline $\begin{array}{l}\text { Quality Assurance Records } \\
\text { System Coordinator }\end{array}$ & Barbara Alegre & $\begin{array}{l}\text { The QA Records System } \\
\text { will provide records } \\
\text { retention and retrieval } \\
\text { services as required by 033- } \\
\text { YMP-QP 3.2 and 033-YMP- } \\
\text { QP 17.0 }\end{array}$ \\
\hline
\end{tabular}

\subsection{Schedule}

The schedule is shown on Figure 1. The schedule shows critical dependencies between $\mathrm{V} \& \mathrm{~V}$ activities. Specific dates are for planning purposes only. The project goal is to complete qualification prior to April 23, 1998. Therefore, approximately one week of float exists in the final qualification date.

\subsection{Budget}

The estimated level of effort for certification of NUFT version 2.0 is 20 staff-weeks. This included the support of YMP staff scientists, software engineers, and project management.

\subsection{Risks}

NUFT is a complex code embodying physical models and numerical techniques that require expert knowledge to use properly. Qualification of NUFT can only assure that NUFT contains the required models and user controls. NUFT is intended to be used by hydrologists and geologists with expertise in numerical solution of PDEs, who can be expected to intervene if the solutions produced are anomalous or unrealistic. Such experts typically use a combination of test problems and successive inclusion of model phenomena to understand and gain confidence in solutions produced by PDE solvers.

NUFT user organizations are responsible for ensuring that the software is appropriately applied. This includes, for example controls to ensure: 1) appropriate distribution of NUFT within their organization, 2) that individual users are appropriately qualified and trained, 3) that NUFT is applied correctly to the intended problems, and 4) that results NUFT produces are properly interpreted. The controls established by the NUFT user organizations are outside of the scope of this ISP.

NUFT is designated as non-critical software (per IEEE Std 1012-1986) for scientific and engineering activities. Undetected failure of NUFT could have an adverse impact on the YMP. Release notes will ensure that NUFT users are aware of risks found during validation of NUFT 2.0 , and their part in mitigating these risks.

More detailed risk analysis and contingency plans are described in the VVP. 


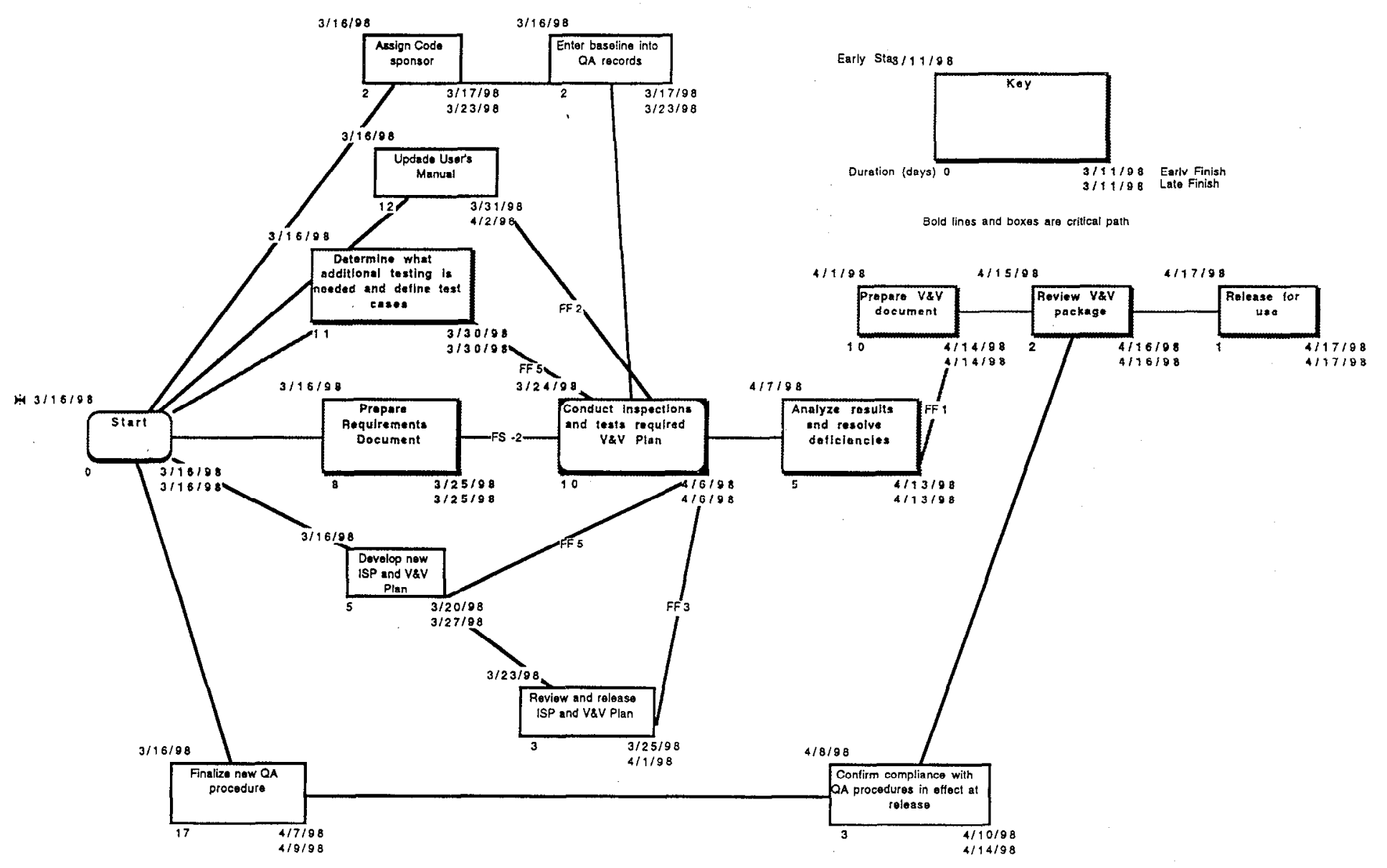

Figure 1 NUFT 2.0 Qualification Schedule 


\section{Required Functions}

The following functions are required by 033-YMP-QP 3.2, and will be performed by the organizations described in Section 2, except for the independent technical reviewer, who will review the product baseline as required by 033-YMP-QP 3.2, Section 4.2.3.

\subsection{Quality Assurance}

The code sponsor is responsible for the execution of the provisions of this ISP.

\subsection{Defect Reporting}

Users, V\&V personnel, Quality Assurance personnel, and Software Configuration Management personnel are responsible for reporting administrative or product defects according to 033-YMP-QP 3.2, Section 4.7. The SCM Coordinator and the CRWMS LLNL Manager are responsible for recording, tracking, and resolving defect reports.

\subsection{Quality Records}

The list of quality assurance records in 033-YMP-QP 3.2, Section 5, as applicable, will be submitted to the YMP Records System.

\subsection{Software Configuration Management}

Software configuration management responsibilities for the NUFT code shall be performed in accordance with 033-YMP-QP 3.2, Sections 4.1-4.7. In addition, NUFT source code baselines shall be maintained as described in the NUFT Configuration Management System Developer's Guide. Source code, electronic documentation, test code, test cases, and test results shall be placed under configuration management. It shall be possible to determine by configuration identification which items are in the field, and it shall be possible to obtain and run regression tests whenever NUFT is modified. A configuration audit of released NUFT packages is a required quality assurance record.

\subsection{Requirements Document}

A requirements document (designated RD by 033-YMP-QP 3.2) that describes what is required of NUFT for the class of problems identified in section 1.2 above will be produced and reviewed. The RD is a required quality assurance record.

\subsection{Software Verification and Validation}

A software verification and validation plan (designated VVP by 033-YMP-QP 3.2) will be written to guide the V\&V team in performing its function. The VVP will meet the requirements of 033-YMP-QP 3.2, and will follow the format described by IEEE Std 1012-1986 as applicable. The VVP is a required quality assurance document.

\subsection{User's Manual}

A user's manual (designated UM by 033-YMP-QP 3.2) will be reviewed in accordance with 033-YMP-QP 3.2 and the VVP for NUFT version 2.0. The existing user's manual consists of three documents ${ }^{\mathrm{ABC}}$, which will be reviewed to ensure that the UM (the composite of the three) covers the subjects required to instruct users how to use the NUFT tool to solve the class of problems defined by the RD for NUFT 2.0. In addition, release notes will become a part of the UM, describing the required user expertise and limitations of use of Version 2.0. The UM is a required quality assurance document. 


\subsection{Verification and Validation Document}

A verification and validation report (designate VVD by 033-YMP-QP 3.2), will be written and will include as enclosures or appendices all completed checklists, baseline software lists, release configuration audit, access control, change, and problem reporting memoranda, and any other interim V\&V products called out in the VVP. The VVD will be structured as a summary that refers to completed supporting documentation that is either appended to the VVD or is retrievable from the QA Records System by control designation.

\subsection{Reviews}

The code sponsor or designee will review progress periodically and at defined milestones in the schedule to ensure that this ISP is being implemented.

\section{Standards and Documentation}

The YMP endorses the use of standards to reduce variation in results and to promote uniformity where such usage makes sense. Standards may be used for guidance, where strict conformity is not required. While the current project is not subject to regulatory approval, results from studies performed with NUFT may have impact on the YMP and may in future be used in constructing a basis for regulatory approval. The use of standards currently endorsed by regulatory agencies can only have positive future effect.

The only industrial standard referenced by this ISP is ANSI/IEEE 1012-1986.

\subsection{Governing Documents}

Pertinent YMP policy documents governing this ISP are:

- 033-YMP-QP 3.2, Revision 4, April 16, 1998, "Software Quality Assurance"

- 033-YMP-QP 17.0, Revision 7-1, December 31, 1996, "Records System"

\subsection{Required Documentation}

- Requirements Document (RD)

- Individual Software Plan (ISP)

- Verification and Validation Plan (VVP)

- User's Manual (UM) (includes installation guide and release notes)

- Verification and Validation Document (VVD)

\subsection{Acquired Documentation}

- "User's Manual for the US1 Module of the NUFT Code, Version 2.0 (Two Phase, Two Component, Isothermal with Passive Gas Phase)," Lawrence Livermore National Laboratory, Livermore CA.

- "User's Manual for the USNT Module of the NUIT Code, Version 2.0 (N-phase, Ncomponent, Thermal)," Lawrence Livermore National Laboratory, Livermore CA.

- "Reference Manual for the NUFT Flow and Transport Code, Version 2.0," Lawrence Livermore National Laboratory, Livermore CA.

These manuals will be released as LLNL reports, e.g., UCRL-ID, as part of the process for releasing NUFT 2.0 . 
*Work performed under the auspices of the U.S. Department of Energy by Lawrence Livermore National Laboratory under Contract W-7405-ENG-48. This work is supported by Yucca Mountain Site Characterization Project, LLNL.

\section{References}

LLNL Yucca Mountain Project procedure 033-YMP-QP 3.2, "Software Quality Assurance"

LLNL Yucca Mountain Project procedure 033-YMP-QP 17.0. "Records System"

ANSI/IEEE Std. 1012-1986, "IEEE Standard for Software Verification and Validation Plans," The Institute of Electrical and Electronic Engineers, New York, NY, 1986.

NUFT Configuration Management System Developer's Guide, QA Records Designation LLYMP9804051.

Deficiency Report, LLNL-98-D-065, April 10, 1998.

A "User's Manual for the US1 Module of the NUFT Code, Version 1.0 (Two Phase, Two Component, Isothermal with Passive Gas Phase)," Lawrence Livermore National Laboratory, Livermore CA, UCID-draft (1993).

B "User's Manual for the USNT Module of the NUFT Code, Version 1.0 (N-phase, Ncomponent, Thermal)," Lawrence Livermore National Laboratory, Livermore CA, UCIDdraft (1995).

C "Reference Manual for the NUFT Flow and Transport Code, Version 1.0," Lawrence Livermore National Laboratory, Livermore CA, UCID-draft (1995). 


\section{LLNL-YMP}

Volume 2. Requirements Document (RD) for the Prediction of Thermo-hydrologic Behavior - NUFT 2.0

Ron Shaffer

April 17, 1998 


\title{
LLNL-YMP
}

\section{Requirements Document (RD) for the Prediction of Thermo-hydrologic Behavior-NUFT 2.0}

\author{
Ron Shaffer
}

April17, 1998

Ron Shaffer

Author

Code Sponsor 


\title{
Requirements Document(RD) for the Prediction of Thermo- hydrologic Behavior - NUFT 2.0 Revision 0, April 17, 1998
}

\author{
Ron Shaffer ph 2-3940
}

\section{Introduction}

The proposed nuclear waste repository site at Yucca Mountain consists of nonuniform faulted and thrusted geologic strata, resulting in differing hydro-geologic units containing fractures of varying permeability. Analysis methods must address temperature variations due to waste packages and fluid flow, as well as fluid and contaminant flow through the porous matrix, including imbibition processes in the fractured porous media. Multi-phase, multi-component fluid flow is central to a complete analysis. A theoretical analysis of the site can be accomplished with a numerical model that represents these physical processes, some of which are coupled. This software Requirements Document $(R D)$ document specifies requirements for existing numerical software that is capable of the solution of a class of coupled mass and heat transport problems in porous geologic media including the cross drift analysis of the Yucca Mountain Repository facility. The candidate software is the NUFT (Nonisothermal Unsaturated-Saturated Flow and Transport model) code which has had wide use in analysis of the Yucca Mountain Repository site. This RD was developed after the initial NUFT software was acquired and after a draft user's manual was developed. The outline of this plan follows guidance provided in Part 5 of ANSI/IEEE 830.

\subsection{Purpose}

The purpose of this Requirements Document is to specify the capabilities needed to perform the mass and energy transport analyses described above and to describe the relevant sections of the user's manual. The $\mathrm{RD}$ is used in conjunction with and to provide direction to the Validation and Verification $(V \& V)$ plan design. The RD specifies that the NUFT code includes the required models while the V\&V ensures that NUFT has the input controls required to select variations of models and address paramcters, boundary conditions, initia! values, mesh, and time stepping that will enable an expert user to gain confidence in NUFT results. Yucca Mountain project participants are the intended audience for this RD.

\subsection{Scope}

The software product addressed by this $\mathrm{RD}$ is the Non-isothermal Unsaturated-saturated Flow and Transport (NUFT) code, a suite of multiphase, multi-component models for numerical solution of nonisothermal flow in porous media. This code uses a selectable set of phenomenological models to solve related partial differential equations (PDEs) numerically.

The scope of this RD is limited to NUFT. Pre and post-processing tools such as RADPRO, YMESH, and XTOOL, which are often used in conjunction with NUFT, will be addressed separately as needed.

Version 2.0 is the first quality controlled release for the NUFT software. Additional releases are anticipated. NUFT Version 2.0 is "acquired software," as defined by 033-YMP-QP 3.2. Version 1.0 was released in February 1998, but that certification is being withdrawn based upon the quality assurance surveillance findings described in LLNL-98-D-065.

\subsection{Definitions}

1.3.1 NUFT - the Nonisothermal Unsaturated-saturated Flow and Transport numerical model. 
1.3.2 XTOOL - a post-processing program to manipulate NUFT output into visual screen and hardcopy images.

1.3.3 stand-alone - a user prepares an input file that has all the directions for the model to run to completion. Initiating the run with the input file is all that is required of the user. There is no model interactively with the user while the program is performing calculations, however, the user can check the progress of the calculations as they are progressing.

1.3.4 PDE - partial differential equations.

1.3.5 Quality Affecting - an activity or analyses is Quality Affecting if a Detennination of Importance Evaluation (DIE) has determined the potential for impact on Q-list items or site characterizationdata.

1.3.6 Q-list - controlled list of items important to pre-closure safety or to waste isolation, YMP/90-55Q.

1.3.7 LLNL POC - Lawrence Livermore National Laboratory Point of Contact for the NUFT code.

\subsection{References}

Two classes of documents are referenced. The first class includes those documents that are binding, or specify form and content of this RD. The second class includes those documents used as guidance for specific requirements in this $\mathrm{RD}$.

\subsubsection{Binding Documents}

1.4.1.1 033 -YMP-QP 3.2, Rev. 4 "Software Quality Assurance, " April 16, 1998. This procedure sets general guidelines that this $\mathrm{RD}$ must meet.

1.4.1.2 ISP-NF-13, Rev. 1, "Individual Software Plan for the Qualification of NUFT, Version 2.0," This ISP specifically implements the general guidelines specified in 033 YMP-QP 3.2.

\subsubsection{Guidance Documents}

Describes useful issues to be addressed in the $\mathrm{RD}$.

1.4.2.1 ANSU/ANS 10.4 "Guidelines for the verification and validation of scientific and engineering computer programs for the nuclear industry,' 1987.

1.4.2.2 ANSI/IEEE Std 830-1993, "IEEE Recommended Practice for Software Requirements Specifications." December 2, 1993.

1.4.2.3 "NUFT Configuration Management System Developer's Guide," QA Records Designation LLYMP9804051 - Describes the existing software configuration management system used for NUFT.

\subsection{Overview of RD}

This RD describes the structure and capabilities NUFT must possess to adequately analyze heat and fluid flow in the complex geology of the Yucca Mountain Repository site for the scope of the problem described in Section 1.2. The RD also provides bounds for the parameters to be validated and verified in the V\&V plan. 


\section{Overall description}

NUFT shall model a wide range of subsurface fluid flow problems. It shall be capable of analyzing both saturated and unsaturated flow including nonisothermal multi-phase, multi-component flow. NUFT shall demonstrate isothermal and nonisothermal, multi-phase fluid flow in one-, two- or three-dimensions.

\subsection{Product perspective}

NUFT is self-contained. It requires data inputs based on the problem being solved. NUFT accepts prescribed formatted input files and outputs formatted files for use by post-processors like XTOOL. For Yucca Mountain applications, data quality should be appropriate for application (e.g., use qualified data for licensing -related applications). No other special interfaces are needed.

\subsubsection{System interfaces}

This release of NUFT runs under the HP UX 10.20 operating system.

\subsubsection{Memory constraints}

NUFT requires about $150 \mathrm{MB}$ to perform calculations on a 20,000 block problem, which is enough blocks to represent a three-dimensional thermo-hydrologic analysis of the Yucca Mountain Repository site. Output files can be large, but they may be stored on any retrievable medium.

\subsubsection{Operations}

NUFT runs as a stand-alone model.

NUFT is restartable.

\subsubsection{Quality affecting analyses}

The use of NUFT on Yucca Mountain quality affecting analyses requires the use of appropriately qualified data.

\subsection{Product functions}

NUFT processes input data from the input file, selects the appropriate heat and fluid flow balance equations, uses a numerical approach to spatially discretize and solve the governing partial differential equation. NUFT user organizations are responsible for ensuring that the software is appropriately applied. This includes, for example controls to ensure: 1) appropriate distribution of NUFT within their organization, 2) that individual users are appropriately qualified and trained, 3) that NUFT is applied correctly to the intended problems, and 4) that results NUFT produces are properly interpreted.

\subsection{User characteristics}

NUFT is a computer code designed to solve PDEs numerically. Dependable results can only be achieved by skilled practitioners. For example, professional judgment is required to select the proper mesh and compatible boundary conditions to adequately simulate the physical phenomena being analyzed at a particular geologic site. More generally, results depend upon initial values, boundary conditions, mesh selection, time step selection, accurate characterization of physical parameters, and choice of modeled phenomena, and only an expert can perform reasonability checks that determine if the numerical solution approximates reality. More than one individual may be required to prepare the NUFT input file. 
NUFT is intended to be used by civil engineers, hydrologists, physicists and/or geologists with expertise in numerical solution of PDEs, who can be expected to intervene if the solutions produced are anomalous or unrealistic. At least one user should have a background in application of numerical methods to analyze non-isnthermal groundwater flow. Such experts typically use a combination of test problems and successive inclusion of model phenomena to understand and gain confidence in solutions produced by PDE solvers. Significant erroneous variation in input values or input values out of range will produce erroneous calculational results that a competent user will recognize and remedy. The user is charged with inspecting the NUFT output file to ensure that the actual input parameter values used in the calculations agree with the user's expectations.

\subsection{Constraints}

For Yucca Mountain "quality affecting" analyses, NUFT will be used under a LLNL QA program which is designed to comply with 10 CFR 50 Appendix B criteria.

Release 2.0 will be certified for installation and operation only on HP workstations with an HPUX 10.20 operating system.

\subsection{Assumptions and dependencies}

The NUFT code will be tested on an HP workstation using the HPUX 10.20 operating system.

NUFT users are assumed to be professional heat and fluid flow scientists with a background in or access to someone who has a background in the numerical solution of nonlinear PDE's.

\subsection{Apportioning of requirements}

A contaminant transport option, a radiant heat transfer option, and a dual permeability (DKM) option, which provides for separate permeabilities for fractures and matrix, will be delayed until a later qualification. In addition, NUFT's non-cartesian coordinate system capability will be included in a later qualification.

\section{Specific Requirements}

The candidate software NUFT shall demonstrate isothermal and nonisothermal, multi-phase fluid flow in one-, two- or three-dimensions in a cartesian coordinate system. It shall be capable of producing the full range of liquid saturations $(S)$ from initially unsaturated $(S=0)$ to fully saturated $(S=1)$. Water mass fraction in the gas phase shall be modeled over the full range from dry $(0)$ to wet $(1)$. The calculation of relative humidity is not valid when liquid saturation is exactly 1 .

NUFT shall be capable of analyzing the following phenomena:

- flow (mass transport or infiltration) in unsaturated media

- flow (mass transport) in saturated media

- coupled mass and energy (heat) transport in geologic media by conduction, convection and diffusion with multiple gas and liquid fluid phases, including phase change

NUFT shall be capable of analyzing these problems for the following different conceptual models of geologic media representative of the Yucca mountain site:

- porous media

- fracturedmedia

- fractured porous media

In intended applications:

- all phenomena may be analyzed in one, two, or three dimensions. 
- NUFT normally will be applied to analyze time-varying transients. Some transient problems may approach a quasi-steady state or steady state solution.

To perform these calculations, NUFT incorporates thermophysical fluid properties for air, water vapor and water. Fluid properties are interpolated from equations that were derived from the ASME steam tables. The properties of air follow the ideal gas law. Fluid mixtures are represented by a scaled linear combination of the individual properties obtained from the ideal gas law and the steam tables. Calculations can be performed over the range of temperature and pressure conditions anticipated in repository analyses (temperatures of 6 to $500 \mathrm{C}$, pressures of $2.67 \times 10^{3}$ to $1.03 \times 10^{7} \mathrm{~Pa}$ ).

Table 1 summarizes NUFT functional capabilities that shall be evaluated during a V\&V program.

Table 1. The particular functional requirements of NUFT

\begin{tabular}{l}
\hline Requirement Satisfied \\
\hline A. Flow processes \\
\hline Pressure-driven gas flow \\
Pressure-driven liquid flow \\
Gravityeffects \\
Capillaryforces \\
Viscousforces \\
\\
\hline B. Constitutive relations \\
\hline Vapor pressure lowering \\
Van Genuchten characteristic curve \\
Temperature dependent capillary pressure \\
\hline C. Phase change/diffusion \\
\hline Phase change \\
Phase(dis)appearance \\
Binary diffusion in gas \\
\hline D. Heat transport \\
\hline Conduction \\
Single phase convection \\
Two phase convection (including heat pipe) \\
\hline E. Dimensionally \\
1-D \\
2-D \\
3-D \\
\hline F. Other \\
\hline
\end{tabular}

Automatic timestepping

Restart capability

For test problems NUFT results will satisfy at least one of the following three criteria: 
(1) Parameter values will be within 5\% of qualified data (analytically obtained parameter values or other qualified parameter values).

(2) Parameter values will be within $5 \%$ of the normalized distance to the qualified time-history curve.

(3) Parameter values will be within $5 \%$ of the parameter variation from qualified data normalized to the parametcr data range.

A NUFT user's manual that provides information on the structure and format of NUFT inputs and outputs shall be provided. In addition, a NUFT theory or reference document that provides information on NUFT calculational methods shall be provided.

\subsection{External interfaces}

Brief descriptions of the input and output files follow. Input and output file formats are specified in the user's manual. The MKS system of units is used in NUFT.

\subsubsection{Input file}

An input file is required to initialize and specify all the material properties and flow variables, the mesh layout, the boundary conditions and time step tolerances that control the time step. Desired output times are also designated in this file. The MKS system of units is used, as described in the user's manual.

\subsubsection{Log file (filename.out)}

$\Lambda \log$ file, designated with a '.out' appended to its name is produccd by NUFT. It echoes the input parameter values and state variables. It also is a history of the run and contains values of parameters that changed the most in the associated time step. This information can be displayed in the "run" window on the monitor. Therefore, the screen can be checked at any time to determine the status of the run.

\subsubsection{Post-processing file (optional file at user's request)}

An output file is required, if requested by the user, to post-process the results of the NUFT calculations. XTOOL is a graphics program that can be used to post process the results. The file can be structured specifically for XTOOL to read and can include, for example, spatial temperatures at each dump time.

\subsubsection{Restart file (optional file at user's request)}

An output file shall be generated as NUFT calculations terminate, if requested by the user. This restart file is then read by NUFT to restart calculations.

\subsection{Functions}

NUFT flags invalid variables that are read from the input file. When underflow or overflow occurs, NUFT execution prematurely terminates with an error message. This signals that there is something amiss with the data in the input file. Error handling or recovery may be provided but is not required in this release of NUFT 2.0 .

At a given point in time in the calculations, a maximum time step is calculated that is intended to limit the size of the changes of solution variables to the specified input tolerances. The time step is then attempted in the calculations and, if the change of any of the solution variables is too large, the time step is reduced and calculations are restarted at the given point in time. This process is repeated as long as the changes in the solution variables are too large. 
Since the quantity of output from a large mesh simulation at all time steps is large, the user selects via the input file which parameters, at which location and time, to put in the post processing file.

3.2.1 The sequence of operations in NUFT (Not a requirement; included for information): Initialize Model:

Read Input Data

Parse input data

Convert to internal linked list

Syntax checking

Check for invalid input variables

Read specification of phases and species

Read properties and functional correlations for species, reactions, and phases

Read material property parameters

Read mesh specification and create initial mesh (or read in mesh file)

Read spatial distribution of material properties

Mapping of material properties to cells

By input or by stochastic generation

Read output options

Read time stepping option and control parameters

Read numerical solution options

Reád initial conditions

Time Loop:

Output variables

Time-step method

Time stcp size

Calculate source terms

Newton-Raphson

Determine the set of active phases, species, and reactions

Jacobian matrix generation

Solve system of linear equations 


\section{Perform line search}

Update solution

Cleanup solution

Reset time-dependent boundary condition cells

The NUFT user's manual and theory or programmer's manual provide information on inputs, outputs and calculational methods.

\subsection{Performance target}

The following information is provided as a goal and is not a specified requirement: NUFT should perform the baseline test cases with calculation time periods of a few hours when performed on a HP $9000 / 780$ workstation. The numerical model is not required to be interactive (therefore, response times are immaterial). However, it is restartable.

\subsection{Software system attributes}

This NUFT shall be installed on HP workstations using the HPUX 10.20 operating system.

*Work performed under the auspices of the U.S. Department of Energy by Lawrence Livermore National Laboratory under Contract W-7405-ENG-48. This work is supported by Yucca Mountain Site Characterization Project, LLNL. 
$\underline{\text { Revision } 1}$

\title{
LLNL-YMP
}

Volume 3. NUFT Version 2.0 Software Verification and Validation Plan

\author{
G. Gary Preckshot
}

April 15, 1998 


\title{
LLNL-YMP
}

\section{NUFT Version 2.0Software Verification and Validation Plan}

\author{
G. Gary Preckshot
}

April 15, 1998

G.Gary Preckshot

Author

John Nitao

Code Sponsor

Michael Fernandez

Date

Date

Date

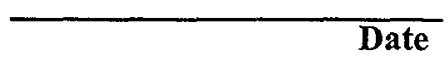




\title{
NUFT Version 2.0SoftwareVerification and Validation Plan
}

\author{
G. Gary Preckshot
}

\author{
Revision 0 \\ April 15, 1998
}

\section{Purpose}

This document documents the plan for software verification and validation of the NUFT code as required by the Individual Software Plan (ISP) for qualification and certification of the NUFT code for problems that include cross drift analysis of the Yucca Mountain Repository facility. The release of the NUFT software for these purposes is termed "Version 2.0." This document will be referred to as the software verification and validation plan, or V\&V plan, and is designated "VVP" by 033-YMP-QP 3.2, the governing YMP procedure.

\subsection{Scope}

\subsubsection{Products Covered By This Plan}

The software product covered by this V\&V plan is the Non-isothermal Unsaturated-saturated Flow and Transport (NUFT) code, Version 2.0, a suite of multiphase, multi-component models for numerical solution of non-isothermal flow and transport in porous media with applications to subsurface contaminant transport problems. This code uses a selectable set of phenomenological models to solve related partial differential equations (PDEs) numerically. Only a subset of the models and capabilities present in NUFT are being certified in Version 2.0.

\subsubsection{Target Platforms}

Version 2.0 will be certified for installation and operation only on target platforms described in the Requirements Document (RD).

\subsubsection{Criticality}

The guiding standard for this $\mathrm{V} \& \mathrm{~V}$ plan' requires mandatory performance of a minimal set of verification and validation tasks if the software covered by the plan is deemed "critical." To support a finding of criticality, failure of the software product must have an impact on safety or have, a credible potential for causing large social or financial loss. There are two application areas with these possible effects:

a) Control or safety system software, where human intervention is precluded by time, observability, or accessibility constraints, and the consequences of failure are unacceptable, or

b) scientific or engineering software whose outputs are depended upon for safety or prevention of great social or financial loss.

The NUFT software is deemed not to be critical under the ANSI/IEEE 1012-1986 definition because NUFT is intended to be used by hydrologists and geologists with expertise in numerical solution of PDEs, who can be expected to intervene if the solutions produced are anomalous or unrealistic. Such experts typically use a combination of test problems and successive inclusion of model phenomena to understand and gain confidence in solutions produced by PDE solvers.

\footnotetext{
' ANSU/IEEE Std 1012-1986, "IEEE Standard for Software Verification and Validation Plans."
} 


\subsubsection{Specific Exclusions From Scope}

NUFT is a computer code designed to solve PDEs numerically. This is a notoriously difficult problem, and dependable results can only be achieved by skilled practitioners of the art. Results depend upon initial values, boundary conditions, mesh selection, time step selection, accurate characterization of physical parameters, and choice of modeled phenomena, and only an expert can perform reasonability checks that determine if the numerical solution approximates reality. The V\&V plan specifically excludes the issue of proper application of the NUFT tool to the intended problem; the V\&V plan specifically includes verification that the NUFT code includes required models and parameter ranges, and has the input controls required to select variations of models, parameters, boundary conditions, initial values, mesh, and time step that will enable an expert user to gain confidence in NUFT results. Although this V\&V plan is not intended to support an application to the NRC for a license to operate the Repository, and such a purpose is excluded from the scope of this plan, failure of NUFT could have an adverse effect on the YMP; therefore, the scope includes suitability of NUFT Version 2.0 for the described usage and purpose of the Activity Plan.

\subsection{Release Objectives}

This is the first release of several for the NUFT software. It is "acquired software," as defined by 033-YMPQP 3.2. The objectives of this V\&V plan are limited to verifying that the NUFT software is suitable for use by qualified professionals to understand and evaluate the effects of the planned Yucca Mountain Repository cross drift test scheduled to begin in mid-April, 1998. V\&V fulfills an unusually prominent role in Version 2.0; there are no design, implementation, or unit test activities planned. Specific verification and validation objectives are broken down as follows:

\subsubsection{Verify That NUFT Implements Required Phenomenological Models and Parameter Ranges \\ 1.2.2. Verify That NUFT Permits Users to Select Variations of Models, Parameters, Boundary Conditions, Initial Values, Mesh, and Time Step}

1.2.3. Perform Static and Dynamic Testing to Locate and Eliminate Common Software Errors

1.2.4. Verify That NUFT Input/Output Formats Conform to the RD

\subsubsection{Verify That NUFT Documentation (Especially User Documentation) Describes Required Features in Adequate Detail}

\subsubsection{Verify That NUFT Can Be Installed on Target Systems}

\section{Referenced Documents}

Two classes of documents are referenced. The first class includes those documents that are binding, or specify the required content of this V\&V plan. The second class includes those documents used as guidance for specific form or requirements in this V\&V plan, or which constitute a technical basis for provisions in this V\&V plan. 


\subsection{Binding Documents}

\subsubsection{3 -YMP-QP 3.2, "Software Quality Assurance"}

Sets general guidelines that ISPs must meet. The YMP requirements document for activities affecting software quality.

2.1.2. ISP-NF-13, Revision 1, April 14, 1998, "Individual Software Plan for the Qualification of NUFT, Version 2.0"

The specific implementation of the general guidelines specified in $033-Y M P-Q P$ 3.2. This document requires the V\&V plan to be guided by ANSI/IEEE Std 1012-1986. It also discusses limitations of scope for Version 2.0, and other activities, notably software configuration management and quality records systems, that are important to software V\&V.

\subsection{Guidance Documents}

\subsubsection{ANSI/IEEE Std 1012-1986, "IEEE Standard for Software Verification and Validation Plans"}

This standard describes the content and format of acceptable software V\&V plans. The format of this V\&V plan is guided by this standard.

\subsubsection{ANSI/ANS-10.4-1987, "Guidelines For The Verification And Validation Of Scientific And Engineering Computer Programs For The Nuclear Industry"}

This standard describes useful issues to be addressed by verification and validation of scientific and engineering programs. Although this guideline addresses programs that are used in the nuclear industry, the similarities between NUFT and codes for simulating nuclear reactors make the guidance in this document applicable. Both NUFT and reactor simulation codes are PDE solvers that incorporate numerous coupled physical models and require skilled users to obtain reliable results.

\subsubsection{NUREG/CR-6430, "Software Safety Hazard Analysis"}

Guidance on hazard analysis methodology applied to software. Useful for analyzing life cycle stage risks.

\subsubsection{NUREG/CR-6421 "A Proposed Acceptance Process for Commercial Off-the-Shelf (COTS) Software in Reactor Applications"}

Guidance on steps to perform when accepting acquire software for a described purpose. This document contains an appendix on software testing techniques.

\subsection{5. "NUFT Configuration Management System Developer's Guide," Date, QA Records Designation LLYMP9804051.}

Describes the existing software configuration management system used for NUFT.

\section{Definitions}

The definitions in 033 -YMP-QP 3.2, ISP-NF-13, Rev. 1, April 14, 1998, and ANSI/IEEE Std 1012-1986 are included by reference. 


\section{Verification and Validation Overview}

\subsection{Organization}

The V\&V organization for NUFT Version 2.0 consists of a V\&V team leader, assisted by one person from FESSP. The V\&V team is augmented from time to time as necessary by other personnel from laboratory organizations such as Computations and Engineering

\subsubsection{Relationship to the YMP}

The V\&V team leader and assistant are FESSP personnel aiding YMP for the duration of qualification of Version 2.0. The YMP maintains the NUFT code in support of scientific and engineering activities at the Yucca Mountain Repository, and may release other versions of NUFT for other engineering purposes. Configuration management and quality records functions will be performed by YMP personnel under existing YMP procedures.

\subsubsection{Intended Users}

The intended users of the results of software V\&V are YMP quality assurance personnel, DOE auditors, and users of the NUFT product.

\subsection{Master Schedule}

The Master Schedule for NUFT Version 2.0 is shown in Figure 1. Figure 2 shows the schedule for V\&V activities. The schedule shows critical dependencies between V\&V activities. Specific dates are for planning purposes only. The project goal is to complete qualification prior to April 23, 1998. Therefore, approximately one week of float exists in the final qualification date.

\subsection{Resources Summary}

For the duration of the project the following resources are available:

\begin{tabular}{|l|l|l|}
\hline Type of Resource & Name & Time Assignment \\
\hline \multirow{4}{*}{ SoftwareEngineer: } & Gary Preckshot (GGP) & 1 FTE \\
\cline { 2 - 3 } & Gary Johnson (GLJ) & 0.25 FTE \\
\cline { 2 - 3 } & Lynn Lewis (LCL) & 0.25 FTE \\
\cline { 2 - 3 } & Al Leibee (JAL) & 0.25 FTE \\
\cline { 2 - 3 } & Carolyn Owens (CAO) & 0.25 FTE \\
\cline { 2 - 3 } & Nancy Storch (NS) & 0.25 FTE \\
\hline Hydrologist & Ron Shaffer(RJS) & 1 FTE \\
\hline \multirow{3}{*}{$\begin{array}{l}\text { Yucca Mountain Hydrologists } \\
\text { (YMH) }\end{array}$} & John Nitao (JJN) & 0.1 FTE \\
\cline { 2 - 3 } & Tom Buscheck (TAB) & 0.1 FTE \\
\cline { 2 - 3 } & Ken Lee(KL) & 0.1 FTE \\
\hline YMP Specialist & Doug Vogt (DKV) & 0.25 FTE \\
\hline
\end{tabular}




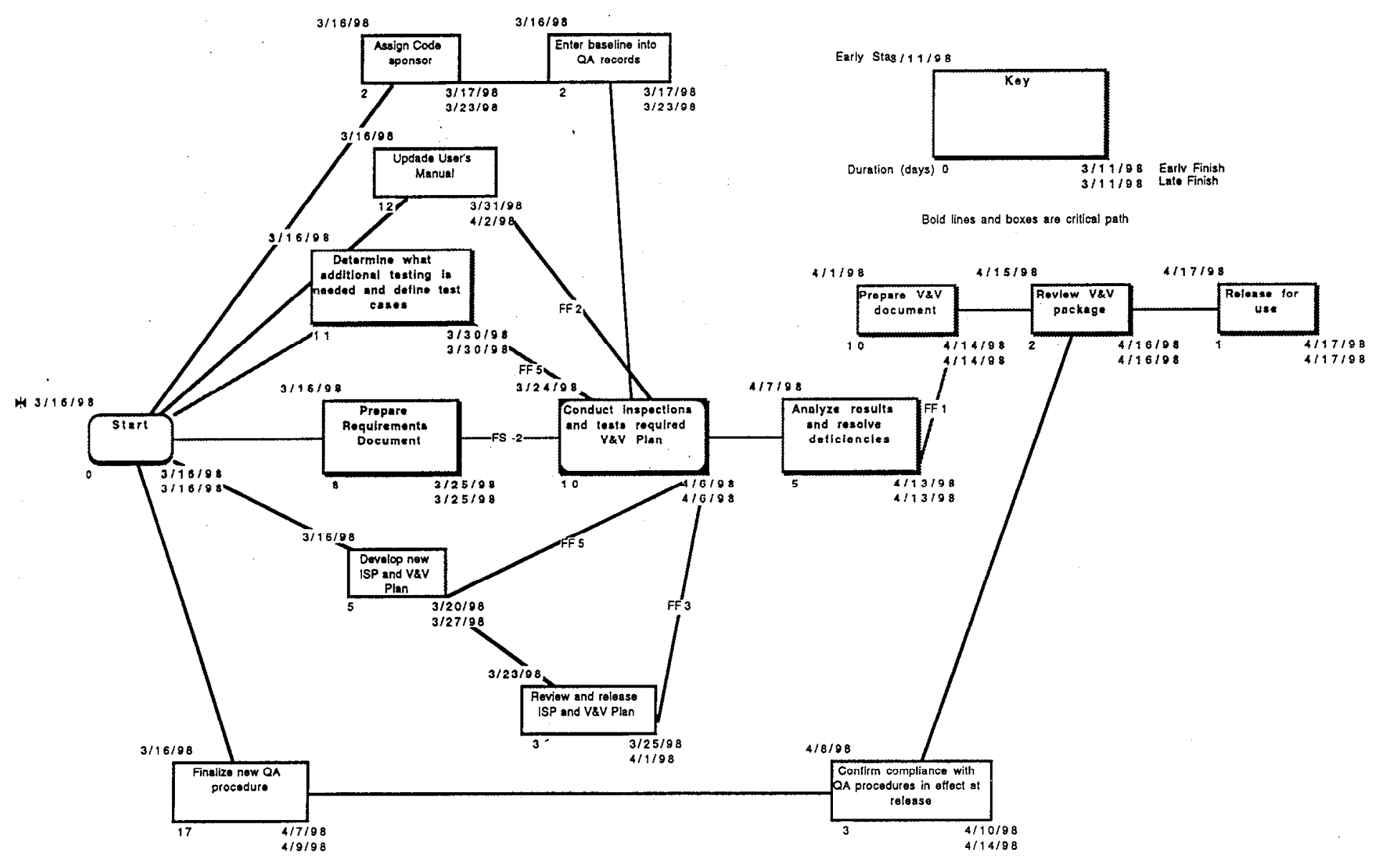

Figure 1 Master Schedule for NUFT Version 2.0 
1. $3 / 30 / 98$

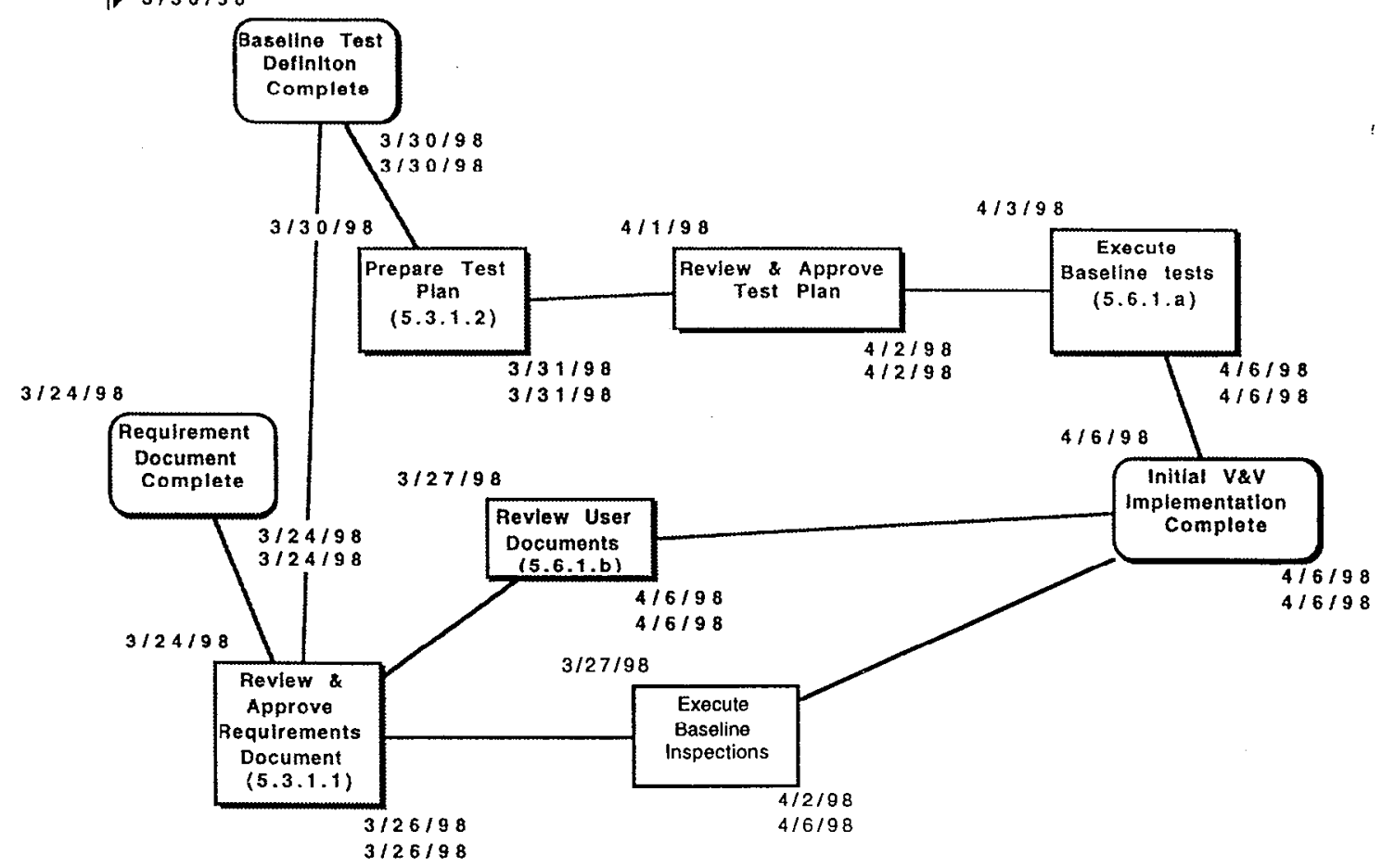

Figure 2 Schedule for V\&V Implementation

\subsection{Responsibilities}

\begin{tabular}{|l|c|c|c|c|c|c|c|c|}
\hline Task & GGP & GLJ & LCL & JAL & NS/CAO & RJS & DKV & YMH \\
\hline V\&V Team Leader & & $\mathrm{x}$ & & & & & & \\
\hline Review Requirements Document & $\mathrm{x}$ & $\mathrm{x}$ & & & & & $\mathrm{x}$ & $\mathrm{x}$ \\
\hline Identify Baseline Tests & & & & & & & & $\mathrm{x}$ \\
\hline Identify of Baseline Inspections & & & $\mathrm{x}$ & & & & & \\
\hline Prepare Test Plan & $\mathrm{x}$ & & & & & & & \\
\hline Review Test Plan & & & & & $\mathrm{x}$ & $\mathrm{x}$ & $\mathrm{x}$ & \\
\hline Execute Baseline Tests & & & $\mathrm{x}$ & $\mathrm{x}$ & & & & \\
\hline Execute Baseline Inspections & & & $\mathrm{x}$ & $\mathrm{x}$ & & & & \\
\hline Resolve Baseline Anomalies & & & $\mathrm{x}$ & $\mathrm{x}$ & & $\mathrm{x}$ & & \\
\hline Prepare V\&V Document & $\mathrm{x}$ & $\mathrm{x}$ & & & & & & \\
\hline Review V\&V Document & & & & & $\mathrm{x}$ & $\mathrm{x}$ & $\mathrm{x}$ & \\
\hline Execute Installation Tests & & & $\mathrm{x}$ & $\mathrm{x}$ & & & & \\
\hline Resolve installation Anomalies & & & $\mathrm{x}$ & $\mathrm{x}$ & & & & \\
\hline
\end{tabular}

Planned responsibilities may be reallocated as necessary provided that independence requirements discussed below and independence requirements of the YMP QA manual are met. The V\&V plan will not be revised to reflect reallocation of responsibilities. Actual personnel involved in any activity will be identified in the activity records. 


\subsection{Tools, Techniques, and Methodologies}

The following tools will be used for code analyses and configuration control of the source code. Specific version information for the tools used will be recorded in file tools_version $2.0 \mathrm{~h}$.doc in the distribution package.

\subsubsection{Unix Lint}

Unix lint will be used for static code analysis to detect uninitialized variables in Version 2.0.

\subsubsection{Unix SCCS}

Unix sccs (source code control system) will be used for maintaining current and previous versions of electronic documents, including source code.

\subsubsection{Insight}

The insight dynamic analysis tool will be used for detecting array bound violations and determining test coverage in Version 2.0.

\section{Life Cycle Verification and Validation}

Bccause NUFT is acquired software, certain life cycle phases are omitted. This would not be the case for software modification, but this V\&V plan does not address software modification.

\subsection{Management of V\&V}

\subsubsection{V\&V Tasks}

Production of the V\&V plan, assignment of resources, control and synchronization of schedule with other activities, periodic review of the $V \& V$ organization against the $V \& V$ plan and to determine $V \& V$ effectiveness.

\subsubsection{Methods and Criteria}

\subsubsection{Methods}

Production of plans, assignments to implement plans, periodic revicws, and corrective action.

\subsubsection{Criteria}

Adequacy of plans, performance of plans, V\&V effectiveness.

\subsubsection{Inputs/Outputs}

\subsubsection{Inputs}

1) Description of products to be verified and validated (i.e. NUFT documentation)

2) Schedule tasking by higher management.

\subsubsection{Outputs}

The primary documentary outputs of $V \& V$ management are the $V \& V$ plan and a V\&V document after the completion of $\mathrm{V} \& \mathrm{~V}$ for a release of a product. For complex, large products being developed in-house, which NUFT is not, periodic reviews at phase boundaries would be performed.

Both the V\&V plan and the V\&V document are controlled quality-assurance records. 


\subsection{Anomaly Reports}

An anomaly report is issued when managerial corrective action is required. Anomaly reports have a suspense date by which time they must be resolved. Anomaly reports and resolution addenda are controlled quality assurance records. See also Sections 6.3 and 7.1.

\subsection{TaskReports}

Tasks for V\&V management generally consist of particular product releases to be verified and validated. Consequently, a task report for $V \& V$ management consists of the $V \& V$ document when the product is released. See also Section 6.1.

\subsection{Phase SummaryReports}

Because of the omission of the concept, design, implementation, and operation and maintenance phase, the V\&V Document will be substituted for V\&V management phase summary reports.

\subsubsection{Schedule}

See section 4.2 .

\subsubsection{Resources}

See the table in Section 4.3 of this plan.

\subsubsection{Risks and Assumptions}

\subsubsection{Risks}

1) Schedule is tight

2) Users may not be sufficiently skilled

3) Test suite may be insufficient

4) Requirements may be missing or inaccurate

5) Code may contain numerical or mathematical errors

6) Mathematical or numerical errors may remain after testing is complete.

\subsubsection{RiskControl}

1) V\&V tasks will be prioritized so that tasks absolutely necessary for Version 2.0 are performed first.

2) Release notes will include a user qualifications section and a necessary user actions section.

3) This risk is always present in any testing-oriented certification and can only be mitigated by involving domain experts in reviews, never eliminated.

4) Domain experts will participate in requirements generation and review.

5) This risk is always present in V\&V of existing software that has not undergone (or has no record of) $V \& V$ during design and implementation phases. It can be mitigated by ensuring knowledgeable uscrs, but not eliminated.

6) This is an unavoidable risk associated with certification of software by testing. It will decrease with time if a rigorous defect reporting and resolution scheme is in place. There is considerable previous experience with NUF'T that can be documented and used to extend the experience base.

\subsubsection{Assumptions}

1) Users are sophisticated enough to recognize most mathematical or numerical errors

2) The requirements match the user's requirements 


\subsubsection{Roles and Responsibilities}

See the table in Section 4.4 of this plan.

\subsection{Concept Phase V\&V}

Not applicable to NUFT, Version 2.0.

\subsection{Requirements Phase V\&V}

Requirements for NUFT Version 2.0 are functional and documentation requirements for an acquired software tool to solve the class of problems that includes the cross drift analysis problem facing the YMP in April, 1998. This differs from the usual V\&V application in that the requirements are not generated by domain experts working directly with developers. Instead, the requirements for NUFT were generated by domain experts, and will be reviewed by the V\&V team to insure that they are testable and can be used to devise acceptance tests for NUFT. These tests will be used to accept or reject NUFT for use in investigating target class problems.

\subsubsection{V\&V Tasks}

1. Requirements Review

Requirements review will be conducted in accordance with Appendix A of 033-YMP-QP3.2,

Revision 4. Greatest emphasis will be placed on the following review points.

a) Verify that the requirements contain the functions required by cross drift analysis (Review Checklist Item $1^{2}$ - Functionality)

i) Objective 1.2.1

b) Verify that the requirements contain usability constraints (Item 3 - Design Constraints)

i) Objective 1.2 .2

ii) Objective 1.2.5

c) Verify that the requirements specify input/output formats and other tool interface compatibility (Item 5 - External Interfaces)

i) Objective 1.2.4

d) Verify that the requirements are internally consistent (Item 8 - Consistency)

e) Verify that requirements contain a list (can be electronic) of components that comprise an installation package for NUFT, and that this list is traceable to a description of NUFT components required to satisfy Objectives 1.2.1, 1.2.2., 1.2.4, and 1.2.5. (Item 7 Verifiability,)

f) Verify that requirements identify the target platform for the NUFT installation package, and that this platform is the platform possessed by NUFT users. (Item 5 - External Interfaces.)

g) Verify that acceptance criteria exist and are stated in a way in which a "pass / fail" decision can be made. (Item 7 - Verifiability.)

2. Test Plan Generation

a) Produce a set of test cases that verifies that NUFT has the functions required by the RD (Objective 1.2.1).

b) Produce a set of test cases (may overlap a)) that verifies that NUFT has the usability features required by the $\mathrm{RD}$ (Objective 1.2.2)

c) Produce a set of test cases (may overlap a)) that verifies that NUFT input/output is accurate and consistent with the formats defined in the RD.

d) Produce a static and dynamic automated code analysis plan for acquired code.

e) Produce a set of derived subjects that user documentation must cover (functions described by the RD). See 033-YMP-QP 3.2, Appendix F.

\footnotetext{
${ }^{2}$ Item numbers refer to check list items in Appendix B of 033-YMP-QP 3.2, which details requirements for $\mathrm{V} \& \mathrm{~V}$ plans.
} 
f) Produce or obtain a set of test case results to compare to the results of executing test cases in a), b), and c).

The Requirements Document Review and the Test Plan are controlled quality assurance records. The Test Plan will be included as Appendix A to this document. The data and/or input sets required to execute the Test Plan are controlled quality assurance records. The test outputs and comparison sets are quality assurancerecords.

\subsubsection{Methods and Criteria}

Independent review of requirements.

The test plan is generated based upon review or requirements. Certain requirements will be demonstrated by execution of benchmark problems using NUFT. Other requirements will be demonstrated by observing attributes of NUFT during testing. Benchmark problems will be include problems for which the analytical soluition is known and problems for which results have been obtained using other validated computer codes (e.g., VTOUGH). The specific test cases are identified and justified in the test plan.

\subsubsection{Inputs/Outputs}

\subsubsection{Inputs}

- Requirements Document specifying

- Functional requirements and acceptance criteria that must be met to support the cross drift analysis and other problems in the target class.

- Usability requirements

- Interfacerequirements

- User Documentation

- Identification of baseline tests necessary to qualify NUFT for the problem class.

- Identification of baseline inspections to be used in qualification of NUFT for the problem class.

\subsubsection{Outputs}

\subsection{Anomaly Reports}

- Anomaly report, resolution schedule, and resolution report for each anomaly discovered. See also Sections 6.3 and 7.1 .

\subsection{TaskReports}

- Requirements Document Review

- Test Plan (Section 8)

- Test Plan Review (Section 8)

See also Section 6.1.

\subsection{Phase Summary Reports}

No phase summary will be produced for Version 2.0. The Requirements Document Review and Test Plan take the place of the requirements phase summary report.

\subsubsection{Schedule}

See Figures 1 and 2 in Section 4.2 of this plan. 


\subsubsection{Resources}

See the table in Section 4.3 of this plan.

\subsubsection{Risks and Assumptions}

No new risks or assumptions are identified for this phase.

\subsubsection{Roles and Responsibilities}

See the table in Section 4.4 of this plan.

\subsection{Design Phase V\&V}

Not applicable to NUFT, Version 2.0.

\subsection{Implementation Phase V\&V}

Not applicable to NUFT, Version 2.0.

\subsection{Test Phase V\&V}

The test phase consists of the execution of the test plan devised during requirements phase V\&V.

\subsubsection{V\&V Tasks}

1) Execute the inspections and tests in the Test Plan and resolve any test anomalies.

2) Evaluate test coverage and determine basis for adequacy.

3) Review the user documentation

\subsubsection{Methods and Criteria}

A copy of NUFT (source, documentation, and executable) will be obtained from the software configuration management organization. Source code will be subjected to inspections consisting of lint static analysis to eliminate uninitialized variables. Executables will be exercised with the insight tool to eliminate array bounds violations. Configuration management-controlled code will be used to execute the baseline test cases, using the Insight tool to monitor test coverage, and the results will be compared to the target test case results. Anomalies will be reported and resolved.

NUFT user documentation will be reviewed to ensure that it covers the subjects listed in the Test Plan.

\subsubsection{Inputs/Outputs}

\subsubsection{Inputs}

- Test Plan

- Controlled NUFT source, user documentation, and executables

\subsubsection{Outputs}

The primary output will be a V\&V Document. The anomaly reports and the Test Plan Execution Report will be incorporated into the V\&V Document for control as quality assurance records. Detailed test records will be separately maintained as quality assurance records and referenced by the V\&V Document.

\subsection{Anomaly Reports}

- Summary anomaly report describing lint and insight testing, results, and corrective actions, if any. 
- Anomaly report, resolution schedule, and resolution report for each anomaly observed during test case execution.

- Summary analysis report, resolution schedule, and resolution report for user documentation deficiencies, if any.

See also Sections 6.3 and 7.1 .

\subsection{Task Reports}

- Summary Test Plan Execution Report.

See also Section 6.1.

\subsection{Detailed Test Records}

- Detailed test procedures.

- Test input, output, and acceptance analyses files.

See also Section 6.1.

\subsection{Phase Summary Reports}

No phase summary will be produced for Version 2.0. The V\&V document will take the place of the phase summary report.

\subsubsection{Schedule}

See Figures 1 and 2 in Section 4.2 of this plan.

\subsubsection{Resources}

See the table in Section 4.3 of this plan.

\subsubsection{Risks and Assumptions}

\subsubsection{Risks}

1) The software tools lint and Insight will miss errors they are supposed to catch.

2) Comparison of test case results with Test Plan expected results will be improperly done.

3) Documentation deficiencies will be missed by the reviewers.

\subsubsection{RiskControl}

1) Software tools are under version control and have a long history of successful use. Any reported tool bugs will be tracked and evaluated to determine impact on NUFT.

2) Test case comparison is automated, reducing the potential for human error.

3) Support will be made available to users to mitigate lack of clarity or content in the documentation. Items missed by the reviewers can be resolved by support personnel.

\subsubsection{Assumptions}

1) The Test Plan is sufficient.

2) Source, documentation, and executables are controlled.

3) Test Plan test case results are correct.

4) Test Plan documentation subjects cover all the subjects necessary for Version 2.0. 


\subsubsection{Roles and Responsibilities}

See the table in Section 4.4 of this plan.

\subsection{Installation and Checkout Phase V\&V}

$\mathrm{V} \& \mathrm{~V}$ of installation and checkout consists of verifying that the delivered package is the package actually verified and validated, and that it can be installed on the target platform successfully.

\subsubsection{V\&V Tasks}

1) Configuration audit.

2) Installation package checkout.

3) Final V\&V report for NUFT Version 2.0.

\subsubsection{Methods and Criteria}

The installation package is audited against the package requirements in the Requirements Document, modified to include changes in configuration identification due to resolved anomalies. Testers install the installation package on a target platform stripped to installation specifications. Testers verify that the target platform includes all other software packages necessary to use NUFT, and that installation programs or scripts work when used in accordance with package installation instructions. Testers verify that user configuration programs or scripts work when used in accordance with user configuration instructions. The final V\&V report will be delivered to the SCM Coordinator for approvals and release as required by 033 YMP-QP 3.2.

\subsubsection{Inputs/Outputs}

\subsubsection{Inputs}

- Installation package

- Requirements Analysis

\subsubsection{Outputs}

\subsection{Anomaly Reports}

- An anomaly report, resolution schedule, and resolution report shall be generated for each configuration anomaly in the installation package.

- A summary anomaly report, and resolution report shall be generated for any anomalies discovered during the test installation.

- An anomaly report and resolution report shall be generated for each user report of installation difficulties.

See also Sections 6.3 and 7.1 .

\subsection{Audited InstallationPackages}

- The final, as-tested, as-passed, installation package for each target platform.

\subsection{Task Reports}

- A combined configuration audit and test installation summary report shall be generated at package release. Documentation of the configuration audit and the installation summary report will be incorporated in the V\&V Document.

See also Section 6.1. 


\subsection{Phase Summary Reports}

- A final $V \& V$ Document summarizing $V \& V$ findings for all $V \& V$ phases shall be prepared at package release.

See also Section 6.1.

\subsubsection{Schedule}

See Figures 1 and 2 in Section 4.2 of this plan.

\subsubsection{Resources}

See the table in Section 4.3 of this plan.

\subsubsection{Risks and Assumptions}

\subsubsection{Risks}

1) The test installer may be too familiar with the product

2) The test installation platform may inadvertently have necessary software packages not normally present on user platforms

3) Knowledge of software configuration identification may not be current

\subsubsection{Risk Control}

1) An independent software engineer will be asked to install the package and configure a user.

2) Part of the installation test will be to verify that the test platform includes only those packages in the installation platform specification.

3) The software configuration management system is automated. Advantage will be taken of automated report generation and Unix automated differencing tools to discover conflicts.

\subsubsection{Assumptions}

1) An installation test platform is available that is stripped to installation specifications.

2) Scripts or installation programs are used to install the software and configure users

\subsubsection{Roles and Responsibilities}

See the table in Section 4.4 of this plan. The code users are responsible for conducting installation tests to confirm that the released software execules properly on their system.

\subsection{Operation and Maintenance Phase V\&V}

Validation of proper installation and operation on the users platform is the responsibility of the user under the control of a OCRWM approved QA program.. Installation testing is to be conducted and documented in accordance with 033-YMP-QP3.2, Revision 4. Maintenance V\&V is not applicable to NUFT, Version 2.0. Maintenance will be covered in a subsequent software maintenance V\&V plan.

\section{Software Verification and Validation Reporting}

Reports required by this plan should have at least the minimum information outlined below.

\subsection{Task Reporting}

Each task report should contain

1) Name(s) of task participant(s)

2) Date of task accomplishment 
3) Name of task

4) Identification of task in this plan (i.e. heading reference)

5) Narrative description of any preconditions

6) Narrative description of any important environmental influences

7) Narrative description of any other influences that affected task performance

8) Narrative description of task

9) Narrative summary of task results (acceptable or not acceptable)

10) Recommendations, if any

In addition, if the task includes testing, the report should identify the following

11) The exact configuration identification of the software tested

12) Description of the test validation method

13) The computer platform, operating system, and any special configuration

The narrative descriptions need not be overlong, but should remark on the gist of task performance, including an assessment of success or failure.

\subsection{Phase Summary Reporting}

No phase summary reports are required. The installation and checkout phase summary report is actually a $\mathrm{V} \& \mathrm{~V}$ final report.

\subsection{Anomaly Reporting}

Each anomaly report should meet the requirements of 033-YMP-QP 3.2 Section 4.7 and Appendix J, and in addition, contain the following information that will permit the anomaly to be tracked by the V\&V team to resolution:

1) Identification of $V \& V$ task during which anomaly was discovered

2) Cause (if known)

3) Recommendations for resolution

4) Recommended resolution schedule

5) Resolution

Each anomaly report will be assigned a unique ID as required by 033-YMP-QP 3.2, and resolution information will be added to the report when the anomaly is resolved.

\subsection{V\&V Final Report}

The V\&V Final Report should contain

1) Name of reporter(s)

2) Date of report

3) Identification of $V \& V$ plan the report is for

4) Identification of the software version and release

5) Identification of the target computer platform(s) and operating system(s)

6) Summary of all life cycle V\&V tasks

7) Summary of task results

8) Summary of anomalies and resolutions

9) Location and names of supporting documents (can be a pointer to a controlled list)

10) Assessment of release quality

11) Recommendations

\section{Verification and Validation Administrative Procedures}

\subsection{Anomaly Reporting and Resolution}

Anomalies shall be reported whenever a significant deviation from expected procedure or test results occurs. Anomalies that are classified as critical to software quality (will impair the ability of software or documentation to meet the objectives listed in Section 1.2 of this plan) must be resolved prior to Version 2.0. 
Anomalies shall be assigned a unique identification and tracked until resolution. The required software configuration management procedure is described in 033-YMP-QP 3.2, Section 4.7. A list of current, unresolved V\&V anomalies shall be maintained by the V\&V team, and unresolved anomalies of long standing may be promoted to critical status based on periodic review of the anomaly's impact.

\subsection{Task Iteration Policy}

Anomalies discovered that invalidate the results of foregoing V\&V tasks shall cause the invalidated tasks, and any tasks dependent upon them to be re-performed or at least reviewed for the potential effects the invalidation may have.

\subsection{Deviation Policy}

This V\&V plan may only be deviated from by revising the plan or by following the procedures described in 033-YMP-QP 2.1 for quality-affecting deviation.

\subsection{Control Procedures}

Electronic. V\&V products are to be placed under management of the NUFT software configuration management system ${ }^{3}$ and identified and tracked by electronic database. All physical records affecting quality are to be placed in the YMP quality assurance records system and tracked by electronic database.

\subsection{Standards, Practices, and Conventions}

No standards other than those already cited have been identified that are applicable to this V\&V plan.

\footnotetext{
${ }^{3}$ See Section 2.2.4. of this plan for reference.
} 


\section{Software Test Plan}

\subsection{Test Plan Identification}

This test plan is for NUFT Version 2.0 for operation on HP Workstations running the HP UX 10.20 operating system.

\subsection{Introduction}

Testing of NUFT 2.0 proceeds from the requirements analysis ('lable l) performed as part of the V\&V plan during the requirements phase of the NUFT 2.0 life cycle. According to the plan, a set of baseline test cases will be derived from requirements analysis and will be used during an automated integrated build/test/release process described by the NUFT Configuration Management System Developer's Guide [part of records package number LLYMP9804051], hereafter referred to as the "SCM Guide." This automated build/test/release process is one third of the V\&V testing responsibility. The second third requires that certain equipment, operational, and installation verifications be done. The last third consists of verifying that documentation covers the use of tested features and any anomalies discovered during the testing process or otherwise known to the V\&V team.

Table 1. Identifiable Requirements From the RD

\begin{tabular}{|l|l|l|}
\hline Section \# & Description & Type \\
\hline $2.0 \mathrm{a}$ & Single phase, saturated and unsaturated flow & $\begin{array}{l}\text { Tech, } \\
\text { Doc }\end{array}$ \\
\hline $2.0 \mathrm{~b}$ & Non-isothermal multi-phase, multi-component flow & $\begin{array}{l}\text { Tech, } \\
\text { Doc }\end{array}$ \\
\hline $2.0 \mathrm{c}$ & $\begin{array}{l}\text { Isothermal and non-isothermal, multi-phase fluid flow in one-, two- or } \\
\text { three-dimensions }\end{array}$ & $\begin{array}{l}\text { Tech, } \\
\text { Doc }\end{array}$ \\
\hline 2.1 & No special interfaces beyond input and output file formats & Op, Doc \\
\hline 2.1 .1 & Runs under the HP UX 10.20 operating system & Equip \\
\hline 2.1 .2 & $\begin{array}{l}\text { Requires about 150 MB to perform calculations on a 20,000 block } \\
\text { thermo-hyrdrologic problem on a UNIX system }\end{array}$ & Equip \\
\hline $2.1 .3 \mathrm{a}$ & $\begin{array}{l}\text { NUFT runs as a stand-alone model (i.e. non-interactive, but user can } \\
\text { checkprogress of calculation) }\end{array}$ & $\begin{array}{l}\text { Tech, } \\
\text { Doc, Op }\end{array}$ \\
\hline 2.1 .4 & $\begin{array}{l}\text { The use of NUFT on Yucca Mountain quality affecting analyses } \\
\text { requires the use of appropriately qualified data }\end{array}$ & Op, Doc \\
\hline 2.2 & $\begin{array}{l}\text { NUFT processes input data from the input file, selects the appropriate } \\
\text { heat and fluid flow balance equations, uses a numerical approach to } \\
\text { spatially discretize and solve the governing partial differential equation }\end{array}$ & $\begin{array}{l}\text { Tech, } \\
\text { Doc, Op }\end{array}$ \\
\hline $2.3 \mathrm{a}$ & $\begin{array}{l}\text { NUFT is intended to be used by civil engineers, hydrologists, } \\
\text { physicists and/or geologists with expertise in numerical solution of } \\
\text { PDEs }\end{array}$ & Op, Doc \\
\hline $2.3 \mathrm{~b}$ & $\begin{array}{l}\text { Significant erroneous variation in input values or input values out of } \\
\text { range will produce signature calculational results that a competent } \\
\text { user will recognize and remedy }\end{array}$ & $\begin{array}{l}\text { Tech, } \\
\text { Doc }\end{array}$ \\
\hline $2.3 \mathrm{c}$ & $\begin{array}{l}\text { The user is charged with inspecting the NUFT filename.out file to } \\
\text { ensure that the actual input parameter values used in the calculations } \\
\text { agree with the user's expectations (see 3.1.2 a). }\end{array}$ & Op, Doc \\
\hline $\begin{array}{l}\text { A contaminant transport option and a dual permeability (DKM) } \\
\text { option, which provides for separate permeabilities for fractures and } \\
\text { matrix, will be delayed until a later qualification. }\end{array}$ & $\begin{array}{l}\text { Op } \\
\text { A non-cartesian coordinate system capability will be included in a }\end{array}$ & Op \\
\hline a & \begin{tabular}{l} 
ateralification. \\
\hline
\end{tabular} &
\end{tabular}

\footnotetext{
${ }^{4}$ Tech - tested by test cases, Op - operational, Doc - documentary, Equip - equipment or software
} 
Table 1. Identifiable Requirements From the RD

\begin{tabular}{|c|c|c|}
\hline Section \# & Description & Type \\
\hline $2.6 \mathrm{c}$ & $\begin{array}{l}\text { A radiant heat transfer capability will be included in a later } \\
\text { qualification. }\end{array}$ & Op \\
\hline $3.0 \mathrm{a}$ & $\begin{array}{l}\text { The candidate software NUFT shall demonstrate isothermal and non- } \\
\text { isothermal, multi-phase fluid flow in one-, two- or three-dimensions } \\
\text { in a cartesian coordinate system }\end{array}$ & $\begin{array}{l}\text { Tech, } \\
\text { Doc }\end{array}$ \\
\hline $3.0 \mathrm{~b}$ & $\begin{array}{l}\text { It shall be capable of producing saturations ( } S \text { ) from initially } \\
\text { unsaturated }(S=0) \text { to fully saturated }(S=1)\end{array}$ & $\begin{array}{l}\text { Tech, } \\
\text { Doc }\end{array}$ \\
\hline $3.0 \mathrm{c}$ & $\begin{array}{l}\text { Water mass fraction in the gas phase shall be modeled over the full } \\
\text { range from dry (0) to wet (1). }\end{array}$ & $\begin{array}{l}\text { Tech, } \\
\text { Doc }\end{array}$ \\
\hline $3.0 \mathrm{~d}$ & $\begin{array}{l}\text { Calculation of relative humidity is not valid when liquid saturation is } \\
\text { exactly } 1 \text {. }\end{array}$ & $\begin{array}{l}\text { Tech, } \\
\text { Doc }\end{array}$ \\
\hline $3.0 \mathrm{e}$ & $\begin{array}{l}\text { NUFT shall be capable of analyzing flow (mass transport or } \\
\text { infiltration) in unsaturated media for porous media, fractured media, } \\
\text { and fractured porous media }\end{array}$ & $\begin{array}{l}\text { Tech, } \\
\text { Doc }\end{array}$ \\
\hline $3.0 \mathrm{f}$ & $\begin{array}{l}\text { NUFT shall be capable of analyzing flow (mass transport) in saturated } \\
\text { media for porous media, fractured media, and fractured porous media }\end{array}$ & $\begin{array}{l}\text { Tech, } \\
\text { Doc }\end{array}$ \\
\hline $3.0 \mathrm{~g}$ & $\begin{array}{l}\text { NUFT shall be capable of analyzing coupled mass and energy (heat) } \\
\text { transport in geologic media with gas and liquid fluid phases, } \\
\text { including phase change, for porous media, fractured media, and } \\
\text { fractured porous media }\end{array}$ & $\begin{array}{l}\text { Tech, } \\
\text { Doc }\end{array}$ \\
\hline $3.0 \mathrm{~h}$ & $\begin{array}{l}\text { In intended applications all phenomena can be analyzed in one, two, } \\
\text { or three dimensions }\end{array}$ & $\begin{array}{l}\text { Tech, } \\
\text { Doc }\end{array}$ \\
\hline $3.0 \mathrm{i}$ & $\begin{array}{l}\text { NUFT can be used to analyze time-varying transients. Transients can } \\
\text { be analyzed to quasi-steady state or steady-state conditions. }\end{array}$ & $\begin{array}{l}\text { Tech, } \\
\text { Doc }\end{array}$ \\
\hline $3.0 \mathrm{j}$ & $\begin{array}{l}\text { NUFT incorporates thermophysical fluid properties for air, water } \\
\text { vapor and water }\end{array}$ & $\begin{array}{l}\text { Tech, } \\
\text { Doc }\end{array}$ \\
\hline $3.0 \mathrm{k}$ & $\begin{array}{l}\text { Fluid properties are interpolated from equations that were derived from } \\
\text { the ASME steam tables }\end{array}$ & $\begin{array}{l}\text { Tech, } \\
\text { Doc }\end{array}$ \\
\hline 3.01 & The properties of air follow the ideal gas law & $\begin{array}{l}\text { Tech, } \\
\text { Doc }\end{array}$ \\
\hline $3.0 \mathrm{~m}$ & $\begin{array}{l}\text { Fluid mixtures use a linear combination of the ideal gas law and the } \\
\text { steam tables }\end{array}$ & $\begin{array}{l}\text { Tech, } \\
\text { Doc }\end{array}$ \\
\hline $3.0 \mathrm{n}$ & $\begin{array}{l}\text { Calculations can be performed over the range of temperatures of } 6 \text { to } \\
\text { about } 500 \mathrm{C}\end{array}$ & $\begin{array}{l}\text { Tech, } \\
\text { Doc }\end{array}$ \\
\hline 3.00 & $\begin{array}{l}\text { Calculations can be performed over the range of pressures of } 2.67 \times 10^{3} \\
\text { to } 1.03 \times 10^{7} \mathrm{~Pa}\end{array}$ & $\begin{array}{l}\text { Tech, } \\
\text { Doc }\end{array}$ \\
\hline $3.0 \mathrm{p}$ & Particular functional requirements mapping is given in Table 2. & Tech \\
\hline $3.0 \mathrm{q}$ & $\begin{array}{l}\text { For benchmark test problems, NUFT results shall satisfy at least one } \\
\text { of the following criteria: } \\
\text { 1) parameter value will be within } 5 \% \text { of the results for the same } \\
\text { problem from either VTOUGH or the analytical solution. } \\
\text { 2) parameter value will be within } 5 \% \text { of a normalized distance to a } \\
\text { standard time history curve } \\
\text { 3) parameter value will be within } 5 \% \text { of parameter variation from } \\
\text { standard data normalized to the parameter data range }\end{array}$ & $\begin{array}{l}\text { Tech, } \\
\text { Doc }\end{array}$ \\
\hline $3.0 \mathrm{r}$ & $\begin{array}{l}\text { A NUFT user's manual that provides information on the structure and } \\
\text { format of NUFT inputs and outputs shall be provided }\end{array}$ & Doc \\
\hline $3.0 \mathrm{~s}$ & $\begin{array}{l}\text { A NUFT theory or reference document that provides information on } \\
\text { NUFT calculational methods shall be provided. }\end{array}$ & Doc \\
\hline $3.1 \mathrm{a}$ & Input and output file formats are specified in the user's manual & Doc \\
\hline $3.1 \mathrm{~b}$ & The MKS system of units is used in NUFT. & $\begin{array}{l}\text { Tech, } \\
\text { Doc }\end{array}$ \\
\hline 3.1 .1 & An input file is required to initialize and specify all the material and & Tech, \\
\hline
\end{tabular}


Table 1. Identifiable Requirements From the RD

\begin{tabular}{|c|c|c|}
\hline Section \# & Description & Type $^{4}$ \\
\hline & $\begin{array}{l}\text { flow variables, the mesh layout, the boundary conditions and a time } \\
\text { step tolerance that controls the time steps. Desired output times are } \\
\text { also designated in this filc. }\end{array}$ & Doc \\
\hline $3.1 .2 \mathrm{a}$ & $\begin{array}{l}\text { A log file, designated with an '.out' appended to its name shall be } \\
\text { produced by NUFT. The log file is a history of the run and shall } \\
\text { contain values of parameters that changed the most in the associated } \\
\text { time step. It also shall echo the state variables as described in the } \\
\text { NUFT } 2.0 \text { Users Manuals. }\end{array}$ & $\begin{array}{l}\text { Tech, } \\
\text { Doc }\end{array}$ \\
\hline $3.1 .2 \mathrm{~b}$ & $\begin{array}{l}\text { Log file information can be displayed in the "run" window on the } \\
\text { monitor. Therefore, the monitor can be checked at any time to } \\
\text { determine the status of the run. }\end{array}$ & Op \\
\hline 3.1 .3 & $\begin{array}{l}\text { An optional output file is required to post-process the results of the } \\
\text { NUFT calculation. One such post-processing program is XTOOL, a } \\
\text { graphics display and printing program. The file can be structured } \\
\text { specifically for XTOOL to read and can include, for example, spatial } \\
\text { temperatures at each dump time. }\end{array}$ & $\begin{array}{l}\text { Tech, } \\
\text { Doc }\end{array}$ \\
\hline 3.1 .4 & $\begin{array}{l}\text { An optional restart file shall be generated at NUFT calculation } \\
\text { tcrmination at the uscr's discretion. The restart file can be read by } \\
\text { NUFT to restart the calculation at the point of termination. }\end{array}$ & $\begin{array}{l}\text { Tech, } \\
\text { Op, } \\
\text { Doc }\end{array}$ \\
\hline $3.2 \mathrm{a}$ & NUFT flags invalid variables that are read from the input file & $\begin{array}{l}\text { Tech, } \\
\text { Doc }\end{array}$ \\
\hline $3.2 \mathrm{~b}$ & $\begin{array}{l}\text { When underflow or overflow occurs, NUFT execution prematurely } \\
\text { terminates with an error message. }\end{array}$ & $\begin{array}{l}\text { Tech, } \\
\text { Doc }\end{array}$ \\
\hline $3.2 \mathrm{c}$ & $\begin{array}{l}\text { Control of time step: At a given point in time in the calculations, a } \\
\text { maximum time step is calculated that is intended to limit the size of } \\
\text { the changes of solution variables to the time step tolerance specified in } \\
\text { the input file. The time step is then attempted in the calculations and, } \\
\text { if the changes of solution variables are too large, the time step is } \\
\text { reduced and calculations are restarted at the given point in time. This } \\
\text { process is repeated as long as the changes in the solution variables are } \\
\text { too large. }\end{array}$ & $\begin{array}{l}\text { Tech, } \\
\text { Doc }\end{array}$ \\
\hline $3.2 \mathrm{~d}$ & $\begin{array}{l}\text { Since the quantity of output from a large mesh simulation at all time } \\
\text { steps is extraordinarily large, the user selects via the input file which } \\
\text { parameters, at which location and time, to put in the post processing } \\
\text { file (see 3.1.3). }\end{array}$ & $\begin{array}{l}\text { Tech, } \\
\text { Doc }\end{array}$ \\
\hline $3.3 \mathrm{a}$ & $\begin{array}{l}\text { This is a performance target: NUFT shall perform the benchmark test } \\
\text { problems (see Section } 8.4 .1 .3 \text { ) without Insight instrumentation on an } \\
\text { HP 9000/780 workstation in several hours. }\end{array}$ & $\begin{array}{l}\text { Tech, } \\
\text { Doc, Op }\end{array}$ \\
\hline $3.3 \mathrm{~b}$ & Operation of NUFT is not required to be interactive & Op \\
\hline $3.3 \mathrm{c}$ & Operation of NUFT is restartable. & Tech \\
\hline $3.4 \mathrm{~b}$ & $\begin{array}{l}\text { NUFT shall be portable to HP workstations using the HP UX } 10.20 \\
\text { operating system. }\end{array}$ & Equip \\
\hline
\end{tabular}

\subsection{Test Items}

1) NUFT Version 2.0 source code

2) NUFT Version 2.0 release package for the HP UX 10.20 operating system

3) NUFT Version 2.0 Insight-instrumented executable for the HP UX 10.20 operating system

4) NUFT Version 2.0 documentation and prospective release notes 


\subsection{Features to be Tested}

\subsubsection{Automated Testing}

A version of the nuft_rel script, subsidiary scripts, and makefiles, all of which have been modified and tested on the target platform, and identified as parts of records package number LLYMP9804051, will be used to test the following features:

\subsubsection{Lint}

Freedom from uninitialized variables and any syntax errors identified by lint.

\subsubsection{Insight}

Freedom from memory bounds violations and determination of baseline test coverage.

\subsubsection{Test Problems}

Functional testing by baseline test cases will demonstrate the feature categories listed in Table 2 . The correspondence between test cases and functional requirements is shown in this table, and was derived by comparing Table 1 of the RD with the file testprbm2.doc, which is attached as an Appendix to this document. This appendix describes the technical details of the test problems. The test problems may in some cases also be applicable to other categories than the ones they are listed as covering. However, they are listed only following requirements that are their primary objectives. This reflects the testing strategy that some test problems should demonstrate only a subset of the required functions, while others should demonstrate functional requirements being satisfied simultaneously. The test problems are also idealized representations designed to show certain physical or software effec ts; it is unlikely that an exact analog would be encountered in nature.

Table 2. The particular functional requirements of NUFT

\begin{tabular}{|c|c|c|}
\hline Category & Requirement to be Satisfied & Test Case(s) \\
\hline \multirow[t]{5}{*}{ A. Flow processes } & Pressure-driven gas flow & bmrk001 \\
\hline & Pressure-driven liquid flow & bmrk017. \\
\hline & Gravityeffects & bmrk015, bmrk016, vsam4 \\
\hline & Capillaryforces & bmrk004, bmrk014 \\
\hline & Viscousforces & vsam2, vsam3 \\
\hline \multirow{3}{*}{$\begin{array}{l}\text { B. Constitutive } \\
\text { relations }\end{array}$} & Vapor pressure lowering & bmrk013 \\
\hline & Van Genuchten characteristic curve & bmrk003, bmrk008 \\
\hline & Temperature dependent capillary pressure & bmrk004 \\
\hline \multirow[t]{3}{*}{$\begin{array}{l}\text { C. Phase } \\
\text { change/diffusion }\end{array}$} & Phase change & $\begin{array}{l}\text { bmrk003, bmrk005, bmrk010, } \\
\text { bmrk011, vsam1 }\end{array}$ \\
\hline & Phase(dis)appearance & bmrk006, bmrk007, vsam1 \\
\hline & Binary diffusion in gas & bmrk012 \\
\hline \multirow[t]{3}{*}{ D. Heat transport } & Conduction only & bmrk002, vsam6 \\
\hline & Single phase convection & bmrk009, vsam6 \\
\hline & Two phase convection (including heat pipe) & $\begin{array}{l}\text { bmrk009, bmrk003, vsam5, } \\
\text { vsam6 }\end{array}$ \\
\hline \multirow[t]{3}{*}{ E. Dimensionality } & $1-D$ & $\begin{array}{l}\text { bmrk001-bmrk017, vsam1, } \\
\text { vsam2, vsam4, vsam6 }\end{array}$ \\
\hline & 2-D & vsam3, vsam5 \\
\hline & 3-D & verif01 \\
\hline F. Other & Automatic timestepping & all vsam problems \\
\hline
\end{tabular}

\footnotetext{
${ }^{5}$ Taken from Table 1 of the RD.
} 
Table 2. The particular functional requirements of NUFT $^{5}$

\begin{tabular}{|l|l|l|}
\hline Category & Requirement to be Satisfied & Test Case(s) \\
\cline { 2 - 3 } & Restart capability & bmrk018 \\
\hline
\end{tabular}

\subsubsection{Testing Observations}

Satisfaction of certain of the requirements cannot easily be demonstrated by test cases, but can be noted by testers during operation of NUFT 2.0 or during the automated execution of baseline test cases. Table 3 is a checklist to be completed by NUFT 2.0 testers that verifies that features listed in the table are part of NUFT 2.0. The following features shall be observed by the tester during validation testing:

Table 3. Observation Checklist

Configuration ID _________ of tested software

\begin{tabular}{|c|c|c|}
\hline Section \# & Observe that & Accepted \\
\hline 2.1 & No special interfaces beyond input and output file formats & \\
\hline 2.1 .1 & Runs under the HP UX 10.20 operating system & \\
\hline 2.1 .2 & $\begin{array}{l}\text { Requires about } 150 \mathrm{MB} \text { to perform calculations on a } 20,000 \text { block } \\
\text { thermo-hyrdrologic problem on a UNIX system }\end{array}$ & \\
\hline $2.1 .3 \mathrm{a}$ & $\begin{array}{l}\text { NUFT runs as a stand-alone model (i.e. non-interactive, but user } \\
\text { can check progress of calculation) }\end{array}$ & \\
\hline $2.3 \mathrm{a}$ & $\begin{array}{l}\text { NUFT is intended to be used by civil engineers, hydrologists, } \\
\text { physicists and/or geologists with expertise in numerical solution of } \\
\text { PDEs }\end{array}$ & \\
\hline $2.3 \mathrm{~b}$ & $\begin{array}{l}\text { Significant erroneous variation in input values or input values out } \\
\text { of range will produce signature calculational results that a } \\
\text { competent user will recognize and remedy }\end{array}$ & \\
\hline $2.3 \mathrm{c}$ & $\begin{array}{l}\text { The user is charged with inspecting the NUFT filename.out file to } \\
\text { ensure that the actual input parameter values used in the } \\
\text { calculations agree with the user's expectations (see } 3.1 .2 \mathrm{a} \text { ). }\end{array}$ & \\
\hline $3.1 \mathrm{~b}$ & The MKS system of units is used in NUFT. & \\
\hline 3.1 .1 & $\begin{array}{l}\text { An input file is required to initialize and specify all the material and } \\
\text { flow variables, the mesh layout, the boundary conditions and a time } \\
\text { step tolerance that controls the time steps. Desired output times are } \\
\text { also designated in this file. }\end{array}$ & \\
\hline $3.1 .2 \mathrm{a}$ & $\begin{array}{l}\text { A log file, designated with an 'out' appended to its name shall be } \\
\text { produced by NUFT. The log file is a history of the run and shall } \\
\text { contain values of parameters that changed the most in the associated } \\
\text { time step. It also shall echo the state variables as described in the } \\
\text { NUFT } 2.0 \text { Users Manuals. }\end{array}$ & \\
\hline $3.1 .2 \mathrm{~b}$ & $\begin{array}{l}\text { Log file information can be displayed in the "run" window on the } \\
\text { monitor. Thercforc, the monitor can be checked at any time to } \\
\text { determine the status of the run. }\end{array}$ & \\
\hline 3.1 .3 & $\begin{array}{l}\text { An optional output file is required to post-process the results of the } \\
\text { NUFT calculation. One such post-processing program is XTOOL, } \\
\text { a graphics display and printing program. The file can be structured } \\
\text { specifically for XTOOL to read and can include, for example, spatial } \\
\text { temperatures at each dump time. }\end{array}$ & \\
\hline$\overline{3.1 .4}$ & $\begin{array}{l}\text { An optional restart file shall be generated at NUFT calculation } \\
\text { termination at the user's discretion. The restart file can be read by } \\
\text { NUFT to restart the calculation at the point of termination. }\end{array}$ & \\
\hline $3.2 \mathrm{a}$ & NUFT flags invalid variables that are read from the input file & \\
\hline $3.2 \mathrm{~b}$ & $\begin{array}{l}\text { When underflow or overflow occurs, NUFT execution prematurely } \\
\text { terminates with an error message. }\end{array}$ & \\
\hline
\end{tabular}




\section{Table 3. Observation Checklist}

Configuration ID

of tested software

\begin{tabular}{|l|l|l|}
\hline Section \# & Observe that & Accepted \\
\hline $3.2 \mathrm{~d}$ & $\begin{array}{l}\text { Since the quantity of output from a large mesh simulation at all } \\
\text { time steps is extraordinarily large, the user selects via the input file } \\
\text { which parameters, at which location and time, to put in the post } \\
\text { processing file (see 3.1.3). }\end{array}$ & \\
\hline $3.3 \mathrm{a}$ & $\begin{array}{l}\text { This is a performance target: NUFT shall perform the benchmark } \\
\text { test problcms (see Section 8.4.1.3) without Insight instrumentation } \\
\text { on an HP 9000/780 workstation in several hours. Testers shall } \\
\text { observe and record the time taken. }\end{array}$ & \\
\hline $3.3 \mathrm{~b}$ & $\begin{array}{l}\text { Operation of NUFT is not required to be interactive } \\
\text { NUFT shall be portable to HP workstations using the HP UX } \\
10.20 \text { operating system. }\end{array}$ & \\
\hline $3.4 \mathrm{~b}$ &
\end{tabular}

\subsubsection{Documentation Review}

The NUFT 2.0 documentation are reviewed to ensure that information required to use NUFT 2.0 for the target problem class is contained in documentation that accompanies the NUFT 2.0 rclcasc package. Table 4 is a checklist of subjects to be covered by documentation.

\section{Table 4. Documentation Subject Checklist}

Documentation configuration $\mathrm{ID}(\mathrm{s})$

Release notes configuration ID

\begin{tabular}{|c|c|c|}
\hline Section \# & Subject & Accepted \\
\hline $2.0 \mathrm{a}$ & Single phase, saturated and unsaturated flow & \\
\hline $2.0 \mathrm{~b}$ & Non-isothermal multi-phase, multi-component flow & \\
\hline $2.0 \mathrm{c}$ & $\begin{array}{l}\text { Isothermal and non-isothermal, multi-phase fluid flow in one-, } \\
\text { two- or three-dimensions }\end{array}$ & \\
\hline 2.1 & No special interfaces beyond input and output file formats & \\
\hline $2.1 .3 \mathrm{a}$ & $\begin{array}{l}\text { NUFT runs as a stand-alone model (i.e. non-interactive, but } \\
\text { user can check progress of calculation) }\end{array}$ & \\
\hline 2.1 .4 & $\begin{array}{l}\text { The use of NUFT on Yucca Mountain quality affecting } \\
\text { analyses requires the use of appropriately qualified data }\end{array}$ & \\
\hline 2.2 & $\begin{array}{l}\text { NUFT processes input data from the input file, selects the } \\
\text { appropriate heat and fluid flow balance equations, uses a } \\
\text { numerical approach to spatially discretize and solve the } \\
\text { governing partial differential equation }\end{array}$ & \\
\hline $2.3 \mathrm{a}$ & $\begin{array}{l}\text { NUFT is intended to be used by civil engineers, hydrologists, } \\
\text { physicists and/or geologists with expertise in numerical } \\
\text { solution of PDEs }\end{array}$ & \\
\hline $2.3 \mathrm{~b}$ & $\begin{array}{l}\text { Significant erroneous variation in input values or input values } \\
\text { out of range will produce signature calculational results that a } \\
\text { competent user will recognize and remedy }\end{array}$ & \\
\hline $2.3 \mathrm{c}$ & $\begin{array}{l}\text { The user is charged with inspecting the NUFT filename.out } \\
\text { file to ensure that the actual input parameter values used in the } \\
\text { calculations agree with the user's expectations (see } 3.1 .2 \mathrm{a} \text { ). }\end{array}$ & \\
\hline $2.6 \mathrm{a}$ & $\begin{array}{l}\text { A contaminant transport option and a dual permeability (DKM) } \\
\text { option, which provides for scparate permeabilities for fractures } \\
\text { and matrix, will be delayed until a later qualification. The } \\
\text { documentation may contain references to this, but the release } \\
\text { notes will specifically exclude this capability from the qualified }\end{array}$ & \\
\hline
\end{tabular}




\section{Table 4. Documentation Subject Checklist}

Documentation configuration ID(s)

Release notes configuration ID

\begin{tabular}{|c|c|c|}
\hline Section \# & Subject & Accepted \\
\hline & uses of NUFT. & \\
\hline $2.6 \mathrm{~b}$ & $\begin{array}{l}\text { A non-cartesian coordinate system capability will be included } \\
\text { in a later qualification. The documentation may contain } \\
\text { references to this, but the release notes will specifically exclude } \\
\text { this capability from the qualified uses of NUFT. }\end{array}$ & \\
\hline $2.6 \mathrm{c}$ & $\begin{array}{l}\text { A radiant heat transfer capability will be included in a later } \\
\text { qualification. The documentation may contain references to } \\
\text { this, but the release notes will specifically exclude this } \\
\text { capability from the qualified uses of NUFT. }\end{array}$ & \\
\hline $3.0 \mathrm{a}$ & $\begin{array}{l}\text { The candidate software NUFT shall demonstrate isothermal } \\
\text { and non-isothermal, multi-phase fluid flow in one-, two- or } \\
\text { three-dimensions in a cartesian coordinate system }\end{array}$ & \\
\hline $3.0 \mathrm{~b}$ & $\begin{array}{l}\text { It shall be capable of producing saturations ( } S \text { ) from initially } \\
\text { unsaturated }(S=0) \text { to fully saturated }(S=1)\end{array}$ & \\
\hline $3.0 \mathrm{c}$ & $\begin{array}{l}\text { Water mass fraction in the gas phase shall be modeled over the } \\
\text { full range from dry (0) to wet (1). }\end{array}$ & \\
\hline $3.0 \mathrm{~d}$ & $\begin{array}{l}\text { Calculation of relative humidity is not valid when liquid } \\
\text { saturation is exactly } 1 \text {. }\end{array}$ & \\
\hline $3.0 \mathrm{e}$ & $\begin{array}{l}\text { NUFT shall be capable of analyzing flow (mass transport or } \\
\text { infiltration) in unsaturated media for porous media, fractured } \\
\text { media, and fractured porous media }\end{array}$ & \\
\hline $3.0 \mathrm{f}$ & $\begin{array}{l}\text { NUFT shall be capable of analyzing flow (mass transport) in } \\
\text { saturated media for porous media, fractured media, and fractured } \\
\text { porous media }\end{array}$ & \\
\hline $3.0 \mathrm{~g}$ & $\begin{array}{l}\text { NUFT shall be capable of analyzing coupled mass and energy } \\
\text { (heat) transport in geologic media with gas and liquid fluid } \\
\text { phases, including phase change, for porous media, fractured } \\
\text { media, and fractured porous media }\end{array}$ & \\
\hline $3.0 \mathrm{~h}$ & $\begin{array}{l}\text { In intended applications all phenomena can be analyzed in one, } \\
\text { two, or three dimensions }\end{array}$ & \\
\hline $3.0 \mathrm{i}$ & $\begin{array}{l}\text { NUFT can be used to analyze time-varying transients. } \\
\text { Transients can be analyzed to quasi-steady state or steady-state } \\
\text { conditions. }\end{array}$ & \\
\hline $3.0 \mathrm{j}$ & $\begin{array}{l}\text { NUFT incorporates thermophysical fluid properties for air, } \\
\text { water vapor and water }\end{array}$ & \\
\hline $3.0 \mathrm{k}$ & $\begin{array}{l}\text { Fluid properties are interpolated from equations that were } \\
\text { derived from the ASME steam tables }\end{array}$ & \\
\hline 3.01 & The properties of air follow the ideal gas law & \\
\hline $3.0 \mathrm{~m}$ & $\begin{array}{l}\text { Fluid mixtures use a linear combination of the ideal gas law } \\
\text { and the steam tables }\end{array}$ & \\
\hline $3.0 \mathrm{n}$ & $\begin{array}{l}\text { Calculations can be performed over the range of temperatures of } \\
6 \text { to about } 500 \mathrm{C} \text { (noted in release notes) }\end{array}$ & \\
\hline $3.0 \mathrm{o}$ & $\begin{array}{l}\text { Calculations can be performed over the range of pressures of } \\
2.67 \times 10^{3} \text { to } 1.03 \times 10^{7} \mathrm{~Pa} \text { (noted in release notes) }\end{array}$ & \\
\hline $3.0 \mathrm{p}$ & Particular functional requirements mapping is given in Table 2. & \\
\hline $3.0 \mathrm{q}$ & $\begin{array}{l}\text { For benchmark test problems, NUFT results shall satisfy at } \\
\text { least one of the following criteria: } \\
\text { 1) parameter value will be within } 5 \% \text { of the results for the } \\
\text { same problem from either VTOUGH or the analytical } \\
\text { solution. }\end{array}$ & \\
\hline
\end{tabular}


Table 4. Documentation Subject Checklist

Documentation configuration ID(s)

Release notes configuration ID

\begin{tabular}{|c|c|c|}
\hline Section \# & Subject & Accepted \\
\hline & $\begin{array}{l}\text { 2) parameter value will be within } 5 \% \text { of a normalized distance } \\
\text { to a standard time history curve } \\
\text { 3) parameter value will be within } 5 \% \text { of parameter variation } \\
\text { from standard data normalizcd to the parameter data range } \\
\text { This will be noted in the release notes. }\end{array}$ & \\
\hline $3.0 \mathrm{r}$ & $\begin{array}{l}\text { A NUFT user's manual that provides information on the } \\
\text { structure and format of NUFT inputs and outputs shall be } \\
\text { provided. }\end{array}$ & \\
\hline $3.0 \mathrm{~s}$ & $\begin{array}{l}\text { A NUFT theory or reference document that provides } \\
\text { information on NUFT calculational methods shall be provided. }\end{array}$ & \\
\hline $3.1 \mathrm{a}$ & Input and output file formats are specified in the user's manual & \\
\hline $3.1 \mathrm{~b}$ & The MKS system of units is used in NUFT. & \\
\hline 3.1 .1 & $\begin{array}{l}\text { An input file is required to initialize and specify all the material } \\
\text { and flow variables, the mesh layout, the boundary conditions } \\
\text { and a time step tolerance that controls the time steps. Desired } \\
\text { output times are also designated in this file. }\end{array}$ & \\
\hline $3.1 .2 \mathrm{a}$ & $\begin{array}{l}\text { A log file, designated with an 'out' appended to its name } \\
\text { shall be produced by NUFT. The log file is a history of the run } \\
\text { and shall contain values of parameters that changed the most in } \\
\text { the associated time step. It also shall echo the state variables as } \\
\text { described in the NUFT } 2.0 \text { Uscrs Manuals }\end{array}$ & \\
\hline $3.1 .2 \mathrm{~b}$ & $\begin{array}{l}\text { Log file information can be displayed in the "run" window on } \\
\text { the monitor. Therefore, the monitor can be checked at any time } \\
\text { to determine the status of the run. }\end{array}$ & \\
\hline 3.1 .3 & $\begin{array}{l}\text { An optional output file is required to post-process the results of } \\
\text { the NUFT calculation. One such post-processing program is } \\
\text { XTOOL, a graphics display and printing program. The file can } \\
\text { be structured specifically for XTOOL to read and can include, } \\
\text { for example, spatial temperatures at each dump time. }\end{array}$ & \\
\hline 3.1 .4 & $\begin{array}{l}\text { An optional restart file shall be generated at NUFT calculation } \\
\text { termination at the user's discretion. The restart file can be read } \\
\text { by NUFT to restart the calculation at the point of termination. }\end{array}$ & \\
\hline $3.2 \mathrm{a}$ & NUFT flags invalid variables that are read from the input file & \\
\hline $3.2 \mathrm{~b}$ & $\begin{array}{l}\text { When underflow or overflow occurs, NUFT execution } \\
\text { prematurely terminates with an error message. }\end{array}$ & \\
\hline $3.2 \mathrm{c}$ & $\begin{array}{l}\text { Control of time step: At a given point in time in the } \\
\text { calculations, a maximum time step is calculated that is } \\
\text { intended to limit the size of the changes of solution variables to } \\
\text { the time step tolerance specified in the input file. The time step } \\
\text { is then attempted in the calculations and, if the changes of } \\
\text { solution variables are too large, the time step is reduced and } \\
\text { calculations are restarted at the given point in time. This } \\
\text { process is repeated as long as the changes in the solution } \\
\text { variables are too large. }\end{array}$ & \\
\hline $3.2 \mathrm{~d}$ & $\begin{array}{l}\text { Since the quantity of output from a large mesh simulation at all } \\
\text { time steps is extraordinarily large, the user selects via the input } \\
\text { file which paraneters, at which location and tine, to put in the } \\
\text { post processing file (see } 3.1 .3 \text { ). }\end{array}$ & \\
\hline $3.3 \mathrm{a}$ & $\begin{array}{l}\text { This is a performance target: NUFT shall perform the } \\
\text { benchmark test problems (see Section 8.4.1.3) without Insight }\end{array}$ & \\
\hline
\end{tabular}




\title{
Table 4. Documentation Subject Checklist
}

Documentation configuration $\mathrm{ID}(\mathrm{s})$

Release notes configuration ID

\begin{tabular}{|l|l|l|}
\hline Section \# & Subject & Accepted \\
\hline & $\begin{array}{l}\text { instrumentation on an HP 9000/780 workstation in several } \\
\text { hours. The release notes should contain the actual performance } \\
\text { number and a method for extrapolating performance to larger } \\
\text { problems. It is the user's responsibility to extrapolate test } \\
\text { platform performance to the user's platform. }\end{array}$ & \\
\hline Operation of NUFT is not required to be interactive & $\begin{array}{l}\text { Operation of NUFT is restartable. The instructions for restart } \\
\text { should be covered in the user manual. }\end{array}$ & \\
\hline $3.3 \mathrm{~b}$ & $\begin{array}{l}\text { NUFT shall be portable to HP workstations using the HP UX } \\
10.20 \text { operating system. }\end{array}$ & \\
\hline $3.4 \mathrm{~b}$ & &
\end{tabular}

\subsubsection{Installation}

The installation test verifies that the installation package can be installed by an average system administrator following installation instructions on the target platform. The installer also verifies that a user environment can be configured correctly by following installation instructions.

\subsection{Features not to be Tested}

1) A contaminant transport option and a dual permeability (DKM) option, which provides for separate permeabilities for fractures and matrix, will be delayed until a later qualification.

2) A non-cartesian coordinate system capability will be included in a later qualification.

3) A radiant heat transfer capability will be included in a later qualification.

\subsection{Approach}

Validation testing is part of the release process described in the SCM Guide. This process meets the configuration management requirements of $033-\mathrm{YMP}-\mathrm{QP} 3.2$ and retains quality records as part of the configuration management package. See Section 2.0 of the SCM Guide for a list of configuration items that are generated and stored in the configuration repository.

Among these configuration items are several C-Shell scripts and makefiles that are used to automate the build/test/release process. The main script is "nuft_rel." A version of nuft_rel will be configured and tested for operation on the target platform with the test problems identified in Section 4 of this test plan. Nuft rel will be run as described in the SCM Guide, and test results will be analyzed by the V\&V team.

Observation by testing personnel will be used to verify satisfaction of certain operational or equipment requirements. Successful completion of the build/test/release process will result in a release package that will be installed on a target platform by a test installer to verify that installation on the target platform can be done by an average system administrator following the installation instructions.

In parallel with automated testing activities, testers will observe test behavior and reviewers will assure that the NUFT 2.0 documentation covers the tested features adequately as described in the above tables. Test personnel should initial in the "Accepted" column of the table when requirements are verified. Problems identified by the tests shall be documented in accodance with sections 6.3 and 7.1 of the V\&V plan.

\subsection{Item Pass/Fail Criteria}

\author{
8.7.1. Lint
}

No lint errors. Lint warnings pass. 


\subsubsection{Insight}

No memory bounds violations. Test coverage report to be reviewed.

\subsubsection{Test Problems}

NUFT produces results for all test problems that meet the accuracy specifications in the Requirements Document (RD), as defined by the nuft rel script (part of records package number LLYMP9804051) and the baseline test case correspondence in Table 2 .

\subsubsection{Test Observations}

NUFT 2.0 will satisfy all checklisted items in Table 3.

\subsubsection{Documentation Review}

The documentation covers the tested features and how to use them adequately. The documentation covers any additional subjects listed in the RD, as defined in Table 4.

\subsubsection{Test Installation}

A competent system administrator is able to install NUFT on a target platform and run the verification problems successfully using only the installation instructions.

\subsubsection{Anomalies}

Anomalies will be reported as required by the applicable sections of the V\&V plan and scheduled for resolution as described in Section 14.2, Item 2, below. Documentation anomalies discovered too late for inclusion in the packaged documentation will be dealt with by inclusion in release notes.

\subsection{Suspension Criteria and Resumption Requirements}

\subsubsection{Release Requirements}

All components of the release must be checked in to the Software Configuration Management System (SCMS) as described by the SCM Guide. A target platform must be available with tar, compiler, linker, lint, and the Insight tool, and the nuft_rel script, and associated scripts must be modified to access the SCMS and run the required tools on the target platform.

\subsubsection{Testing Suspension Criteria}

One of the pass/fail criteria is evaluated as fail. If it makes sense to continue testing so as to find a batch of failures, then testing may continue to discover additional failures so that failures may be fixed en masse with one iteration through the configuration management system.

\subsubsection{Testing Resumption Requirements}

If the anomaly that caused the testing suspension is evaluated as a type a) anomaly (see Section 17.2, Item 2)), the code must be fixed as described in the SCM Guide, and testing must be restarted from scratch. If the anomaly is evaluated as a type b) anomaly, testing may be resumed at the point of the anomaly using the work-around devised for avoiding it.

\subsection{Test Deliverables}

\subsubsection{Automated Tests}

The automated NUFT release archiving command generates ${ }^{6}$, among other things, the following configuration items:

- Release Bill of Materials

${ }^{6}$ SCM Guide, Section 6.2.1 
- Release Version History File

- Release Validation Test Log

- Release Validation Test Differences Log

- Release Source Validation Log

- Release Test Coverage Report

\subsubsection{Test Results Analysis}

A review of the results of the automated tests listed in Section 9.1, including configuration identifications of test results and the released package.

\subsubsection{Test Observations}

Completed checklist as in Table 3, signed by test personnel.

\subsubsection{Documentation Review}

Completed checklist as in Table 4, signed by reviewing personnel.

\subsubsection{Installation Test}

Certification of successful installation, accompanied by any applicable anomaly reports, signed by the test installer.

\subsection{Environmental Needs}

The test system in an office environment supplied with commercial power.

\subsection{Responsibilities}

See the responsibilities table in Section 4.4 of the main part of this document, and the ISP $^{7}$

\subsection{Staffing and Training Needs}

See the resource table and the responsibilities table in Sections 4.3 and 4.4, respectively, of the main part of this document. There are no outstanding training needs for this version.

\subsection{Schedule}

See the Master Schedule in Section 4.2 of the main part of this document.

\subsection{Risks and Contingencies}

\subsubsection{Risks}

1) The instrumented executable runs very slowly

2) Anomalies may be discovered during test

\subsubsection{Contingency Plans}

1) The uninstrumented executable will be run first to identify anomalies quickly and the instrumented executable will be run only after a clean uninstrumented run.

2) Anomalies will be classified as a) must be fixed, or b) can be worked around by procedures in release notes. Only a)-type anomalies will require a code fix and retest. B)-type anomalies will be reported and noted in release notes, and scheduled for resolution before the next version of NUFT is released.

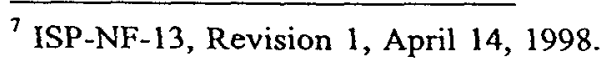




\subsection{Completed Test Documentation Approvals}

\begin{tabular}{lc}
\hline Test Executer & Date \\
& \\
\hline Reviewer & Date \\
& \\
\hline Code Sponsor & Date
\end{tabular}

Date

*Work performed under the auspices of the U.S. Department of Energy by Lawrence Livermore National Laboratory under Contract W-7405-ENG-48. This work is supported by Yucca Mountain Site Characterization Project, LLNL. 


\subsection{Test Plan References}

LLNL Yucca Mountain Project procedure 033-YMP-QP 3.2, "Software Quality Assurance"

NUFT Configuration Management System Developer's Guide, April 10, 1998, part of records package number LLYMP9804051

Individual Software Plan for the Qualification of NUFT

for the Cross Drift Analysis Problem, ISP-NF-13, Revision 1, April 14, 1998. 


\section{Appendix \\ Integration Test Case Suite}

\section{Kenrick Lee}

The Integration Test Case Suite consists of twenty-five test cases. The cases are identified as bmrk001 through bmrk018, vsam1 through vsam6, and verif01. The problems are one- two- or fully threedimensional, solved using the Cartesian coordinate system. The code is tested by benchmarking against VTOUGH, or by comparison with analytical solutions. The purpose and a brief description of each test case are presented in the following table.

The test cases are generally two-phase and two-component problems that may be thermal or isothermal. The phases are liquid and gas, and the components are water and air. Air is treated as a pseudocomponent with averaged properties. In some problems, it is necessary to isolate a physical process for examination by turning off other processes. For example, vapor diffusion and liquid flow are turned off to examine code performance in modeling gas flow driven by pressure gradients. In other problems, multiple processes are addressed.

The goal with bmrk001 through bmrk017 is to test the code's handling of specific hydrologic and thermal processes that are central to nuclear waste isolation at Yucca Mountain. In some cases, a single process is isolated and examined, while in others, two or three process are examined. The code is tested by benchmarking against VTOUGH. All bmrk problems are one-dimensional.

The code's restart capability is tested using bmrk018. This test case is identical to bmrk001, except that execution is stopped at an earlier time and a restart file printed. The restart file is then used to prescribe initial conditions for a restart run.

The vsam test cases, vsam1 through vsam6, are one- and two-dimensional problems taken from the TOUGH manual. These problems were used in testing the TOUGH code, and later, in the qualification of VTOUGH. Like the bmrk problems, the vsam problems examine many of the thermo-hydrologic processes that are important to nuclear waste disposal at the proposed repository site in Yucca Mountain. However, vsam2 through vsam6 address more practical problems that examine mulltiple interacting processes, in ID and 2D. As with the bmrk's, the code is tested by benchmarking against VTOUGH.

The capability of NUFT to accurately solve three-dimensional problems is tested using verif01. This test problem addresses heat conduction in a rectangular parallelpiped. The numerical solution is compared with an analytical solution. 


$\begin{array}{ll}\text { Test Case Name } & \text { Process or Feature } \\ \text { bmrk001 } & \begin{array}{l}\text { Flow of gas phase } \\ \text { driven by gas pressure } \\ \text { gradient }\end{array}\end{array}$

bmrk002 Thermal conduction

bmrk003

bmrk004

Vaporization and movement of water by a heat source

Liquid phase flow by

\section{$\underline{\text { Description }}$}

One-dimensional flow of gas by pressure gradient established by setting higher pressure at one boundariy.

One-dimensional

No. of elements: 5

Isothermal: yes

Initial conditions: all non-boundary elements set to pressure of $1.0 \mathrm{e} 5 \mathrm{~Pa}$ and liquid saturation of 0.5

Boundary conditions: Pressure at one end fixed at $5.0 \mathrm{e} 5 \mathrm{~Pa}$

Relative permeability: set to 0.0 for liquid, preventing liquid flow, linear option for gas

Diffusion: tortuosity factors set to 0.0 , preventing diffusion

Capillary pressure: set to zero.

Gravity:off

One-dimensional thermal conduction driven by heat source.

No. of elements: 5

Isothermal: no

Initial conditions: all non-boundary elements set to $23.0 \mathrm{C}$

Boundary conditions: right end temperature fixed at $23.0 \mathrm{C}$

Source term: Heat source of $1,360 \mathrm{~W}$ at left end

Relative permeability: both fluids set to zero, preventing fluid flow

Diffusion: all tortuosity factors set to zero, preventing diffusion

Capillary pressure: set to zero.

Gravity:off

One-dimensional vaporization and movement of water driven by heat source.

No. of elements: 5

Isothermal: no

Initial conditions: non-cannister elements set to temperature $23.0 \mathrm{C}$, pressure $1.0 \mathrm{e} 5 \mathrm{~Pa}$, and liquid saturation 0.5

Boundary conditions: right end locked at temperature $23.0 \mathrm{C}$, pressure $1.0 \mathrm{e} 5 \mathrm{~Pa}$, and liquid saturation 0.5

Source term: Heat source of $1,360 \mathrm{~W}$ at left end

Relative permeability: both fluids set to 1.0

Capillary pressure: function defined using van Genuchten parameters

Diffusion: all tortuosity factors set to zero, preventing diffusion

Gravity:off capillary imbibition
One-dimensional liquid flow by capillary imbibition.

No. of elements: 5

Isothermal: yes

Initial conditions: all elements set to temperature $23.0 \mathrm{C}$, pressure $1.0 \mathrm{e} 5$ $\mathrm{Pa}$, and liquid saturation 0.001

Boundary conditions: right end temperature fixed at $23.0 \mathrm{C}$, pressure 1.0e5, and liquid saturation 0.9999

Relative permeability: table option for both fluids

Capillary pressure: table option used

Diffusion: all tortuosity factors set to zero, preventing diffusion Gravity:off 


\begin{tabular}{|c|c|c|}
\hline Test Case Name & $\begin{array}{l}\text { Process or Feature } \\
\text { Tested }\end{array}$ & Description \\
\hline bmrk005 & $\begin{array}{l}\text { Equivalent continuum } \\
\text { option }\end{array}$ & $\begin{array}{l}\text { One-dimensional equivalent continuum model of vaporization by heat } \\
\text { source } \\
\text { No. of elements: } 5 \\
\text { Isothermal: no } \\
\text { Initial conditions: non-cannister elements set to temperature } 23.0 \mathrm{C} \text {, } \\
\text { pressure } 1.0 \mathrm{e} 5 \mathrm{~Pa} \text {, and liquid saturation } 0.5 \\
\text { Boundary conditions: right end fixed at temperature } 23.0 \mathrm{C} \text {, pressure } \\
1.0 \mathrm{e} 5 \text {, and liquid saturation } 0.5 \\
\text { Source term: Heat source of } 1,360 \mathrm{~W} \text { at left end } \\
\text { Relative permeability: equivalent continuum option for liquid and gas } \\
\text { Capillary pressure: equivalent continuum parameters used } \\
\text { Diffusion: all tortuosity factors set to zero, preventing diffusion } \\
\text { Gravity:off }\end{array}$ \\
\hline bmrk006 & $\begin{array}{l}\text { Pressurization by } \\
\text { injection of air }\end{array}$ & $\begin{array}{l}\text { Pressurization of cell by air injection, } 1 \mathrm{D} \\
\text { No. of elements: } 2 \\
\text { Isothermal: yes } \\
\text { Initial conditions: elements set to temperature } 23.0 \mathrm{C} \text {, pressure } 1.0 \mathrm{e} 5 \mathrm{~Pa} \text {, } \\
\text { and liquid saturation } 0.5 \\
\text { Boundary conditions: none } \\
\text { Source tern: air injected into left node at } 1.60 \mathrm{e}-6 \mathrm{~kg} / \mathrm{s} \\
\text { Relative permeability: linear option for liquid and gas } \\
\text { Capillary pressure: set to zero } \\
\text { Diffusion: all tortuosity factors set to zero, preventing diffusion } \\
\text { Gravity:off }\end{array}$ \\
\hline bmrk007 & $\begin{array}{l}\text { pressurization by } \\
\text { injection of steam }\end{array}$ & $\begin{array}{l}\text { Injection of steam into cell containing dry air, ID } \\
\text { No. of elements: } 2 \\
\text { Isothermal: no } \\
\text { Initial conditions: elements set to temperature } 23.0 \mathrm{C} \text {, pressure } 1.0 \mathrm{e} 5 \mathrm{~Pa} \text {, } \\
\text { and liquid saturation } 0.0 \\
\text { Boundary conditions: none } \\
\text { Source term: steam of enthalpy } 2.556 \mathrm{e} 6 \mathrm{~J} / \mathrm{kg} \text { injected into left element at } \\
1.60 \mathrm{e}-6 \mathrm{~kg} / \mathrm{s} \\
\text { Relative permeability: linear option for liquid and gas } \\
\text { Capillary pressure: set to zero } \\
\text { Diffusion: all tortuosity factors set to zero, preventing diffusion } \\
\text { Gravity:off }\end{array}$ \\
\hline bmrk008 & $\begin{array}{l}\text { Van Genuchten } \\
\text { characteristiccurve } \\
\text { option }\end{array}$ & $\begin{array}{l}\text { Heat injection to test van Genuchten characteristic curve option, } 1 \mathrm{D} \\
\text { No. of elements: } 2 \\
\text { Isothermal: no } \\
\text { Initial conditions: elements set to temperature } 23.0 \mathrm{C} \text {, pressure } 1.0 \mathrm{e} 5 \mathrm{~Pa} \text {, } \\
\text { and liquid saturation } 0.5 \\
\text { Boundary conditions: none } \\
\text { Source term: heat influx of } 1,362 \mathrm{~W} \text { into left element } \\
\text { Relative permeability: van Genuchten option for liquid and gas phases } \\
\text { Capillary pressure: van Genuchten option } \\
\text { Diffusion: all tortuosity factors set to zero, preventing diffusion } \\
\text { Gravity:off }\end{array}$ \\
\hline
\end{tabular}




\section{$\underline{\text { Test Case Name }}$}

bmrk009

bmrk010

bmrk011

\section{Process or Feature}

\section{Tested}

Transport of steam

Condensation from $100 \%$ water vapor

Condensation of water from $50 \%$ water vapor in air

\section{$\underline{\text { Description }}$}

Transport of steam from a cell containing steam at $100 \%$ quality to a cell saturated with dry air at lower temperature and pressure, $2 \mathrm{D}$

No. of elements: 2

Isothermal: no

Initial conditions: cooler element set to temperature $23.0 \mathrm{C}$, pressure

$1.0 \mathrm{e} 5 \mathrm{~Pa}$, and liquid saturation 0.0

Boundary conditions: steam element fixed at temperature $200.0 \mathrm{C}$,

pressure $1.0 \mathrm{e} 5 \mathrm{~Pa}$, and liquid saturation 0.0

Source term: no

Relative permeability: set to 1.0 for liquid and gas phases

Capillary pressure: set to zero

Diffusion: all tortuosity factors set to zero, preventing diffusion

Gravity:off

Test condensation in element with $100 \%$ water vapor, $1 \mathrm{D}$

No. of elements: 2

Isothermal: no

Initial conditions: cooler element containing dry air set to temperature $23.0 \mathrm{C}$, pressure $1.0 \mathrm{e} 5 \mathrm{~Pa}$, and liquid saturation 0.0

Boundary conditions: steam element fixed at temperature $200.0 \mathrm{C}$, pressure $1.0 \mathrm{e} 5 \mathrm{~Pa}$, and liquid saturation 0.0

Source term: no

Relative permeability: set to 1.0 for liquid and gas phases

Capillary pressure: set to zero

Diffusion: all tortuosity factors set to zero, preventing diffusion Gravity:off

Condensation of water from a cell containing air with $50 \%$ water vapor into a cell containing dry air at lower temperature

No. of elements: 2

Isothermal: no

Initial conditions: cooler element containing dry air set to temperature $23.0 \mathrm{C}$, pressure $1.0 \mathrm{e} 5 \mathrm{~Pa}$, liquid saturation 0.0

Boundary conditions: Hot element fixed at temperature $200.0 \mathrm{C}$, pressure $1.0 \mathrm{e} 5 \mathrm{~Pa}$, liquid saturation 0.0 , and mass fraction air 0.5 Source term: no

Relative permeability: set to 1.0 for liquid and gas phases

Capillary pressure: set to zero

Diffusion: all tortuosity factors set to zero, preventing diffusion

Gravity:off 


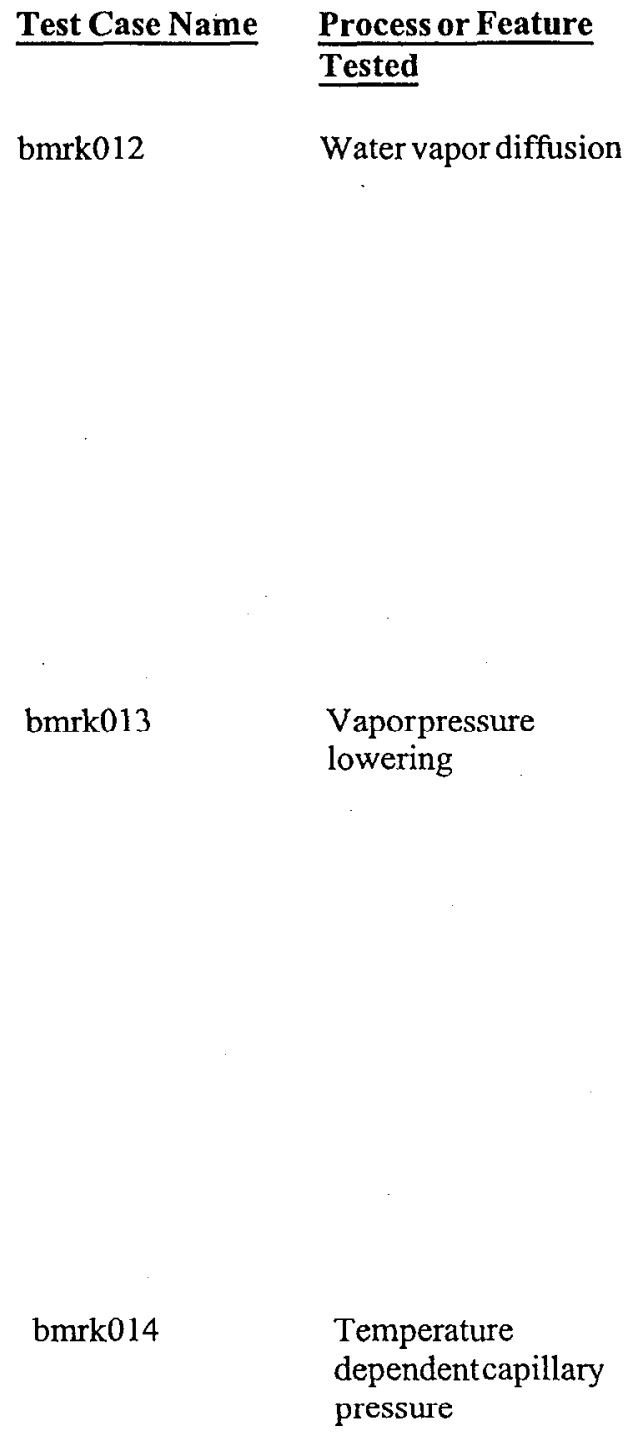

\section{Description}

Vapor diffusion from cell saturated with steam to two-phase cells at lower temperature

No. of elements: 5

Isothermal: no

Initial conditions: cooler elements set to temperature $23.0 \mathrm{C}$, pressure

$1.0 \mathrm{e} 5 \mathrm{~Pa}$, liquid saturation 0.5

Boundary conditions: Hot element fixed at temperature $200.0 \mathrm{C}$, pressure $1.0 \mathrm{e} 5 \mathrm{~Pa}$, liquid saturation 0.0 , and mass fraction air 0.0

Source term: no

Permeability: set to zero to turn off liquid anf gas flow

Capillary pressure: set to zero

Diffusion: gas phase tortuosity factor 0.2 , and liquid turned off by setting to zero

Gravity:off

Vapor diffusion with vapor pressure lowering option activated

No. of elements: 5

Isothermal: no

Initial conditions: the four non-boundary elements are set to temperature

23.0 C, pressure 1.0e5 $\mathrm{Pa}$, liquid saturation 0.0 , and mass fraction water in gas 0.0

Boundary conditions: Boundary element fixed at temperature $200.0 \mathrm{C}$, pressure $1.0 \mathrm{e} 5 \mathrm{~Pa}$, liquid saturation 0.0 , and mass fraction water in gas

1.0

Source term: no

Permeability: set to zero to turn off liquid anf gas flow

Capillary pressure: van Genuchten option

Diffusion: gas phase tortuosity factor set to 0.2 , and liquid turned off by setting to zero

Gravity:off

Temperature dependent capillary pressure option used in vaporization and movement of water by heat source, $1 \mathrm{D}$.

No. of elements: 5

Isothermal: no

Initial conditions: non-cannister elements set to temperature $23.0 \mathrm{C}$, pressure $1.0 \mathrm{e} 5 \mathrm{~Pa}$, and liquid saturation 0.5

Source term: Heat source of $1,360 \mathrm{~W}$ at left end (cannister element)

Boundary conditions: right end temperature fixed at $23.0 \mathrm{C}$

Relative permeability: both fluids set to 1.0

Capillary pressure: function defined using van Genuchten parameters

Diffusion: all tortuosity factors set to zero, preventing diffusion

Gravity:off 


\section{Test Case Name Process or Feature Tested \\ bmrk015 \\ Gas phase flow by gravity}

.

bmrk016

bmrk017

bmrk018

vsam1
Liquid phase flow by gravity

Liquid phase flow by phasepressure gradient

Restart capability

Phase transitions, component (dis)appearances

\section{$\underline{\text { Description }}$}

Model effect of gravity on gas phase movement along vertical column, $1 \mathrm{D}$. No. of elements: 10

Isothermal: yes

Initial conditions: all elements set to temperature $23.0 \mathrm{C}$, pressure $1.0 \mathrm{e} 5$ $\mathrm{Pa}$, and liquid saturation 0.05

Boundary conditions: bottom element locked at initial conditions

Source term: no

Relative permeability: linear option used for liquid and gas, with value of zero for liquid in saturation range of problem

Capillary pressure: set to zero

Diffusion: all tortuosity factors set to zero, preventing diffusion

Gravity: on

Model effect of gravity on liquid phase movement along vertical column, $1 \mathrm{D}$.

No. of elements: 10

Isothermal: yes

Initial conditions: all elements set to temperature $23.0 \mathrm{C}$, pressure $1.0 \mathrm{e} 5$

$\mathrm{Pa}$, and liquid saturation 0.95

Source term: no

Boundary conditions: bottom element fixed at temperature $23.0 \mathrm{C}$, pressue $1.0 \mathrm{e} 5 \mathrm{~Pa}$, and liquid saturation 0.90

Relative permeability: linear option used for liquid and gas

Capillary pressure: set to zero

Diffusion: all tortuosity factors set to zero, preventing diffusion

Gravity: on

Flow of liquid phase driven by phase pressure gradient, $1 \mathrm{D}$.

No. of elements: 5

Isothermal: yes

Initial conditions: elements set to temperature $23.0 \mathrm{C}$, pressure $1.0 \mathrm{e} 5 \mathrm{~Pa}$, and liquid saturation 1.0e-4 for cannister (at left end) and 0.5 for other elements

Boundary conditions: boundary element at right fixed at temperature

23.0 C, pressue 5.0e5 $\mathrm{Pa}$, and liquid saturation 0.99

Source term: no

Relative permeability: linear option for liquid, zero for gas

Capillary pressure: set to zero

Diffusion: all tortuosity factors set to zero, preventing diffusion

Gravity:off

Test restart run capability by rerunning bmrk001 with break and restart at $60,000 \mathrm{~s}$

Other test case features identical to bmrk001

Fifteen one- and two-element subproblems that test the code's ability to handle phase transitions, component appearances and disappearances.

Details available in input file. $1 D$. 


\section{Test Case Name}

vsam2

vsam3

vsam4

vsam5
Process or Feature Tested

Infiltration into a semi-infinite tube

Two-dimensional infiltration with gravity
Two-phase flow of water and steam to a geothermal well (Garg's Problem)
Strongly heat-driven flow in partially saturated porous or fracturedmedium

\section{Description}

Test of infiltration into a semi-infinite tube, $1 D$

No. of elements: 82

Isothermal: yes

Initial conditions: all non-boundary elements set to temperature $20.0 \mathrm{C}$, pressure $1.0 \mathrm{e} 5 \mathrm{~Pa}$, and liquid saturation 0.44

Boundary conditions: left boundary element fixed at temperature $20.0 \mathrm{C}$, pressue $1.0 \mathrm{e} 5 \mathrm{~Pa}$, and liquid saturation 1.0

Source term: no

Relative permeability: linear option used for liquid and gas

Capillary pressure: table option

Diffusion: all tortuosity factors set to zero, preventing diffusion

Gravity:off

Test of 2D infiltration with gravity.

No. of elements: 164

Isothermal: yes

Initial conditions: all non-boundary elements set to temperature $20.0 \mathrm{C}$, pressure $1.0 \mathrm{e} 5 \mathrm{~Pa}$, and liquid saturation 0.40

Boundary conditions: lliquid saturation varies with depth along left

boundary

Source term: no

Relative permeability: linear option used for liquid and gas

Capillary pressure: table option

Diffusion: all tortuosity factors set to zero, preventing diffusion

Gravity: on

Radial flow of water and steam to a geothermal well, ccounting for phase transitions and propagating fronts, $1 \mathrm{D}$.

No. of elements: 50

Isothermal: yes

Initial conditions: all elements set to temperature $300.0 \mathrm{C}$, pressure

$9.0 \mathrm{e} 6 \mathrm{~Pa}$, and liquid saturation 1.0

Boundary conditions: none, adiabatic

Source term: well at left end extracts fluid at $14.0 \mathrm{~kg} / \mathrm{s}$

Relative permeability: tablulation of Corey's Curve for liquid and gas

Capillary pressure: zero

Diffusion: all tortuosity factors set to zero, preventing diffusion

Gravity:off

Strongly heat-driven flow generated by waste package in partially saturated medium with discrete fracture, $2 \mathrm{D}$.

No. of elements: 180

Isothermal: yes

Initial conditions: matrix saturation 0.8 , fracture saturation 0.009878 ,

temperature $26.0 \mathrm{C}$, pressure $1.0 \mathrm{e} 5 \mathrm{~Pa}$

Boundary conditions: outer boundary elements clamped at initial conditions

Source term: table of time-varying heat generation rate supplied for waste package

Relative permeability: van Genuchten option for matrix, linear for fracture

Capillary pressure: van Genuchten for matrix, table for fracture

Diffusion: 0.25 tortuosity factor for gas, zero for liquid

Gravity:off 


\section{$\underline{\text { Test Case Name }} \quad \frac{\text { Process or Feature }}{\text { Tested }}$ \\ vsam6 \\ Heat pipe with non- condensible gas (after Udell and Fitch)}

verif01

$3 D$ heat conduction in

\section{$\underline{\text { Description }}$}

Test of code's ability to model the heat pipe phenomenon due to twophase countercurrent flow in a porous medium, 1D

No. of elements: 91

Isothermal: no

Initial conditions: saturation 0.50 , pressure $1.0133 \mathrm{e} 5 \mathrm{~Pa}$, temperature $70.0 \mathrm{C}$

Boundary conditions: left boundary element has liquid saturation, pressure $1.0133 \mathrm{e} 5 \mathrm{~Pa}$, temperature $70.0 \mathrm{C}$

Source term: $100.0 \mathrm{~W}$ from heater at right end

Relative permeability: tabulate function of Fatt and Klikoff for liquid and gas

Capillary pressure: table option

Diffusion: 0.50 tortuosity factor for gas, zero for liquid Gravity:off parallelpiped
Test of code's ability to handle fully three-dimensional grids to solve thermo-hydrologic problems, 3D

No. of elements: 512

Isothermal: no

Initial conditions: temperature $20.0 \mathrm{C}$, pressure $1.0 \mathrm{e} 5 \mathrm{~Pa}$, liquid saturation 0.0

Boundary conditions: front face temperature $100.0 \mathrm{C}$, remaining five faces $20.0 \mathrm{C}$

Source term: no

Relative permeability: zero for both liquid and gas

Capillary pressure: zero

Diffusion: zero tortuosity factor for both gas and liquid

Gravity:off 


\title{
LLNL-YMP
}

\section{Volume 4. Verification and Validation Document (VVD) for NUFT Version 2.0}

\author{
Gary Preckshot
}

April 30, 1998 


\section{Verification and Validation Document (VVD) for NUFT Version 2.0}

April 30, 1998 


\section{Verification and Validation Document (VVD) for NUFT Version 2.0 April 30, 1998}

\section{Names of reporters}

Gary Lynn Johnson

G. Gary Preckshot

\section{Date of report}

April 30, 1998

\section{Identification of V\&V plan}

"NUFT Version 2.0 Software Vcrification and Validation Plan," Revision 0, April 15, 1998, required by "Individual Software Plan for the Qualification of NUFT Version 2.0," ISP-NF-13, Rev. 1, April 14, 1998. The ISP was written pursuant to "Software Quality Assurance," 033 -YMP-QP 3.2, Revision 4. V\&V activities were completed in accordance with $\mathrm{CN} 3.2-4-1$ to QP 3.2. This change notice was issued after the release of the ISP. The change to the procedure imposed a requirement that test cases developed independently of the code developer be included in the test suite. Addendum 2 to Appendix 2 of this report discusses the independence of test cases. See Section 9.1 for precise records identification.

\section{Identification of the software version and release}

NUFT Version 2.0h. See Section 9.5.1 for precise package identification. Version $2.0 \mathrm{~h}$ was produced for use on HP workstations. In the future NUFT 2.0 may be released for quality-affecting work on other platforms. The letter designator in the version number will indicate the target platform.

\section{Identification of the target computer platform(s) and operating system(s)}

HP workstations running the HPUX 10.20 operating system.

\section{Summary of all life cycle V\&V tasks}

\subsection{V\&V Management}

\subsubsection{Production of the V\&V plan}

A V\&V plan was required to allocate resources and control the scheduling and performance of V\&V tasks. Management was constrained by the available budget and time.

\subsubsection{Assignment of resources}

$V \& V$ management was required to identify trained personnel and assign them to appropriate V\&V tasks. In addition, YMP management is required to ensure familiarization of incoming personnel with YMP QA procedures.

\subsubsection{Control and synchronization of schedule with other activities}

$V \& V$ management was required to synchronize and coordinate $V \& V$ tasks with those of requirements writers, independent reviewers, and testers. 


\subsubsection{Review to determine V\&V effectiveness}

$V \& V$ management is required to review its own effectiveness and the effectiveness of the $V \& V$ effort with the objectives of identifying shortfalls and changes that will produce more effective $V \& V$ in the future.

\subsection{Requirements Phase}

\subsubsection{Requirements Analysis}

The V\&V team was required to analyze the requirements document $(R D)$ and related documents to determine tests and other techniques that will demonstrate suitability of NUFT 2.0 for its intended application.

\subsubsection{Test Plan Generation}

The V\&V team was required to generate a test plan within the capabilities of the current YMP program that would best demonstrate the objectives of the V\&V Plan.

\subsection{Test Phase}

\subsubsection{Automated Test Execution}

Testers, under the direction of the test plan (Section 8 in the V\&V Plan) were required to execute automated tests under script control on a representative workstation.

\subsubsection{Test Observations}

While executing automated tests, testers were required to observe certain operational features of NUFT 2.0 .

\subsubsection{Test Results and Test Coverage Review}

The automated testing produces several reports. Testers were required to review these reports to determine acceptability.

\subsubsection{Documentation Review}

Reviewers were required to examine existing NUFT 2.0 documentation to ensure that it or release notes cover the capabilities of NUFT 2.0 that were tested and which are being certified.

\subsection{Instállation and Checkout Phase}

\subsubsection{Configuration audit}

A configuration audit was required to assure that the delivered package is built from the same source code as was tested. The configuration audit was also required to assure that the delivered package contains ancillary files and data required by the delivery specification.

\subsubsection{Installation testing at LLNL}

An independent software engineer was required to install the NUFT 2.0 package on a representative target platform following only the instructions in the installation package, configure a user to use NUFT, and run the installation verification test problems successfully.

\subsubsection{Final V\&V report for NUFT Version 2.0}

This report was required to be written by the V\&V team as the final step in the release process. 


\section{Summary of task results}

\subsection{V\&V Management}

V\&V Management performed acceptably given task constraints. Management's assessment of performance is given in Section 10 and recommendations are given in Section 11. No anomaly reports were generated.

\subsection{Requirements Phase}

The requirements analysis was performed acceptably. A test plan that met the requirements was generated and reviewed, and was found acceptable. YMP hydrologists identified a set of test cases that was acceptable to them. No anomaly reports were generated.

\subsection{Test Phase}

All test cases executed successfully except for 11 time-location points that were out of tolerance in tests vsam5 and vsam6. These out of tolerance points were analyzed in software problem / defect report NUFT2.0-0498-3 and judged to have no adverse effect. Static analysis, dynamic analysis, and test coverage analysis also identified anomalies that were reviewed and found to be acceptable. Copies of the anomaly reports and evaluation are contained in Appendix 8A.

The observation checklist from the V\&V Plan was acceptably completed. The completed checklist is included in Appendix 8C.

All testing records are contained on magnetic media in records package LLYMP9804051.

Appendix 3 describes testing activities.

Documentation review was successfully completed for the user's manual, the theory manual, and the release notes. Appendix 4 describes the documentation review.

\subsection{Installation and Checkout Phase}

\subsubsection{Configuration audit}

The configuration audit was successfully completed. Appendix 5 describes the configuration audit and results.

\subsubsection{Installation testing at LLNL}

The LLNL installation test was successfully completed. Appendix 6 describes the his test and the test results

\section{Summary of anomalies and resolutions}

Copies of all anomaly reports are provided in Appendix 8A.

\subsection{V\&V Management}

No anomaly reports were generated.

\subsection{Requirements Phase}

No anomaly reports were generated.

\subsection{Test Phase}

The anomalies were reported during the test phase. Appendix $8 \mathrm{~A}$ contains copies of the anomaly reports. 
1. Testing identified 11 points at which the test acceptance criteria were not met. These were reviewed and found not to affect the acceptability of the codc. The test discrepancies and acceptance are documented in Software Problem / Defect Report NUFT2.0h-0498-3. Details of the discrepancy analysis are contained in the NUFT $2.0 \mathrm{~h}$ readme file.

2. The Lint static analysis issued approximately 20 diagnostic warnings. These were reviewed and found to be benign or outside of the scope of the analysis. The lint analysis and evaluation of findings is documented in Software Problem / Defect Report NUFT2.0h-0498-4.

3. Test coverage reports produced by insight showed that test coverage was about $28 \%$ of statement coverage. This is a very low degree of coverage. It is believed that the low test coverage resulted from the testing effort covered only a limited set of NUFT functionality. Although the VVP does not establish acceptance criteria for test coverage, it was judged that the combination of low test coverage, the inability to do a timely analysis of test coverage to determine the percent of coverage for the required applications, and the lack of path coverage information should be documented via an anomaly report. This is judged to be an acceptable anomaly because: 1) The actual coverage of the code elements needed to support the release requirements is higher, 2) YMP hydrologists believe that the set of test problems executed are adequate to demonstrate the functionality required to support the cross drift analysis, and 3) the NUFT 2.0h release notes require independent reasonability checks on the results of analyses using the code. The coverage analysis findings are documented in Software Problem / Defect Report NUFT2.0h-0498-2. 4. One dynamic analysis exception was identified by the insight analysis. This exception was documented in a Software Problem / Deficiency Report and disposition as accept-as-is. Appendix 8A contains copies of the problem report. The dynamic analysis findings are documented in Software Problem / Defect Report NUFT2.0h-0498-1.

\subsection{Installation and Checkout Phase}

\subsubsection{Configuration audit}

No anomaly reports were generated.

\subsubsection{Installation testing at LLNL}

No anomaly reports were generated.

\section{Identification and names of supporting documents}

With the exception of item 9.1.1, all documents and magnetic media identified below are contained in records package LLYMP9804051. Item 9.1.1 is maintained as part of the LLNL YMP QA procedures.

\subsection{Governing Documents}

\subsection{1 "Software Quality Assurance," 033 -YMP-QP 3.2, Revision 4, CN 3.2-1.}

9.1.2 "Individual Software Plan for the Qualification of NUFT Version 2.0," ISPNF-13, Rev. 1, April 14, 1998.

\subsection{3 "NUFT Configuration Management System Developer's Guide," April 10,} 1998.

\subsection{4 "NUFT Version 2.0 Software Verification and Validation Plan," Revision 0 , April 15, 1998}




\subsection{5 "Requirements Document (RD) for the Prediction of Thermo-hydrologic Behavior," Revision 0, April 17, 1998.}

\subsection{Controlled Source Documents}

\subsubsection{Source Code and Make Files}

List of controlled source and make files and version ids that are compiled to the NUFT executable. This is a reference to a software configuration control configuration item. These are contained on magnetic media included in the records package.

\subsubsection{NUFT Documentation}

ISP-NF-13, Rev. 1 indicated that three users manuals would be issued. Based upon a review of the requirements document it was determined that only two of the three manuals are required to support the functionality certified in release $2.0 \mathrm{~h}$. Therefore, only the following two manuals are included in this release.

UCRL-MA-130651 "Reference Manual for the NUFT Flow and Transport Code, Version 2.0." UCRL-MA-130653, "User's Manual for the USNT Module of the NUFT Code, Version 2.0."

Release notes were developed that describe the installation of NUFT $2.0 \mathrm{~h}$ and that describe precautions and limitations in the use of NUFT $2.0 \mathrm{~h}$. These release notes will accompany the distribution of the software. A copy of the release notes is included in Appendix 8B.

\subsection{Controlled Testing Materials}

\subsection{1 nuft_rel and Related Testing Scripts}

These are contained on magnetic media included in the records package.

Record package ID or configuration ID: LLYMP9804051

\subsubsection{Test Problems}

Test problem files are listed in the release bill of materials. Input files are identified with file names of the form *.inX. Expected output files (target files) are identified with file names of the form *.th. Test output files (actual results) are identified with file names of the form ${ }^{*}$.ex.

\subsection{Testing Results}

These are files produced by the nuft_rel script. These are contained on magnetic media included in the records package. Record package ID:_LLYMP9804051

\subsubsection{Release Bill of Materials}

Configuration ID: nuft2.0h.bom 1.2

\subsubsection{Release Dynamic Analysis}

Configuration ID: insight_test2.0h.log 1.1

\subsubsection{Release Validation Test Differences Log}

Configuration ID: test 2.0h.log 1.1

All test cases included in the test run $\log$ (see 9.4.2) completed successfully except as noted in this $\log$. 


\subsubsection{Release Static Analysis}

Configuration ID: lint_test2.0h.log 1.1

\subsubsection{Release Test Coverage Report}

Configuration ID: tca_2.0h.rpt 1.1

\subsubsection{Analysis of Test Coverage and Test Results}

Configuration ID: insight_test2.0h.log 1.1

\subsection{Installation and Checkout}

\subsubsection{Installation Package Generation Script}

This script is contained on magnetic media included in the records package. Record package ID:

LLYMP9804051, Configuration ID: MakeDist 1.5.

\subsubsection{LLNL Installation Report}

See Appendix 6.

\subsection{V\&V Task Reports}

\subsubsection{V\&V Management}

See Appendix 8.

\subsubsection{Requirements Phase}

See Appendices 1 and 2.

\subsubsection{Test Phase}

\subsubsection{Automated Test Execution}

See Appendix 3.

\subsubsection{Test Observations}

See Appendix 3.

\subsubsection{Test Coverage Review}

Test coverage reports showed that test coverage was about $28 \%$ of statement coverage. This is a very low degree of coverage. It is believed that the low test coverage resulted from the testing effort covered only a limited set of NUFT functionality. Although the VVP does not establish acceptance criteria for test coverage, it was judged that the combination of low test coverage, the inability to do a timely analysis of test coverage to determine the percent of coverage for the required applications, and the lack of path coverage information should be documented via an anomaly report. Section 8.3 above discusses the anomaly report issued.

\subsubsection{Documentation Review}

See Appendix 4 


\subsubsection{Installation and Checkout Phase}

\subsubsection{ConfigurationAudit}

See Appendix 5.

\subsubsection{Installation at Livermore}

See Appendix 6.

\subsubsection{V\&VFinal Report}

This document, which satisfies Section 5.7.1, Item 3, of the V\&V Plan.

\subsection{V\&V Anomaly Reports}

See Appendix 8A

\section{Assessment of release quality}

NUFT $2.0 \mathrm{~h}$ successfully completed testing to verify that the NUFT software is suitable for use by qualified professionals to understand and evaluate the effects of the planned Yucca Mountain Repository cross drift test.

The suitability of NUFT $2.0 \mathrm{~h}$ for other applications is unknown at this time for the following reasons:

1. Limited test coverage

2. Limited design information

3. Limited design process information

4. Limited documented operating experience data

Resolving these limitations for release $2.0 \mathrm{~h}$ was not possible given the schedule constraints.

While the NUFT software completed tests that YMP hydrologists stated were sufficient to meet the requirements for NUFT Version 2.0, very limited test coverage was achieved as reported by the Insight test coverage tool. Before NUFT is released for broader use the relationship of the test coverage achieved to functions provided by the NUFT code should be understood, a more complete assessment of the effectiveness of the tests coverage performed, and additional test cases executed if necessary.

The limited amount of design information available at this time makes it impossible to extrapolate the results of testing conducted for this release to certify NUFT for broader use based upon an understanding of which specific code elements were and were not tested. Some level of design documentation will need to be developed to support the evaluation test coverage.

The limited amount of information about the design process (in progress design reviews and testing for example) makes it impossible to extrapolate the results of testing conducted for this release to certify NUFT for broader use based upon a judgment that the quality of the tested code elements are representative of the code as a whole. A more thorough understanding of the development process quality is needed to support decisions about the amount of testing needed to form a judgment about broader use.

Considerable operating experience has been obtained in through the use of NUFT for non-quality -affecting activities. All operating experience is undocumented and anecdotal at this time and thus cannot be credited in certifying NUFT for broader use. The development of documented operating experience and establishing the applicability of experience to the specific NUFT version released for quality-affecting use would significantly support the case for broader application of the code.

Immediately upon completion of this release the $V \& V$ team will undertake efforts for more complete $V \& V$ necessary to release NUFT for a broader range of quality-affecting analyses. 


\section{Recommendations}

1) Release NUFT Version 2.0 in "as-is" form. LLNL YMP hydrologists have stated that the test cases are adequate for the purposes they employ NUFT, and the release notes contain cautions for other YMP personnel who have not been part of the qualification effort.

2) Conduct a post-mortum review of 033-YMP-QP 3.2 using software professionals to identify process improvements. Specific improvements identificd for consideration include the following.

a) The QP should allow for the existence of Test Plans separate from the Verification and Validation Plan.

b) Independent review forms should require identification of the document reviewed as opposed to the code package under review.

c) Sign-off requirements on the independent review forms should be consistent between the forms. Ideally the only signature that should be required is that of the independent reviewer.

d) A review checklist should be added for release notes.

3) Evaluate licensing risks and expected NRC requirements for analytical codes and how this might apply to future releases of NUFT.

4) Identify development process data, operating experience data, and design data or reverse engineering practices that can supplement data we have for the current version of NUFT. Use this information to establish a documented QA history for NUFT and to improve either test coverage or understanding of test coverage of the qualification test suite. Identify the usage profiles for NUFT and compare with test suite coverage. Use the design or reverse-engineering data to evaluate change requests.

5) Develop a project position on the acceptability of treating future versions of NUFT as acquired code vs. requiring future development under the YMP QA program. As part of developing this position NRC's views about the acceptability of an organization with QA responsibilities under subpart G of 10 CFR 60 reaccquiring code from themselves should be determined.

6) Future schedules should allow for sequential completion of the requirements document and the test plan to minimize wasted effort involved in trying to maintain the requirements analysis current with evolving requirements.

7) The testers should have a dedicated HP workstation. Testing went significantly slower than anticipated because of the need to share CPU time with other users and because of the ability of the host organization to run at higher priority than the validation testing/

8) A workable configuration management system needs to be established and made part of the established QA records management process. The process of maintaining software configuration items on removable electronic media in the QA records system is not a practical approach over the long run.

9) More up-front training and a little better coordination of requirements analysis and requirements document production would be helpful.

10) YMP should select a standards framework to form the basis for future qualification activities. Candidate frameworks include the IEEE suite of software engineering standards, the ANS 10 series of software engineering standards, and the ISO 9000 and IEC / ISO JTC 1 SC7 suite of software engineering standards.

11)Where testing plays so large a role in the acceptability of a technical software product, domain experts should be involved early and be thoroughly briefed on determining a documented relationship between test cases and identifiable functional requirements.

*Work performed under the auspices of the U.S. Department of Energy by Lawrence Livermore National Laboratory under Contract W-7405-ENG-48. This work is supported by Yucca Mountain Site Characterization Project, LLNL. 


\section{Appendix 1 \\ Task Report \\ Requirements Analysis}

\section{Name(s) of task participant(s)}

Gary Preckshot, Gary Johnson, Ron Shaffer, Ken Lee, Tom Buscheck

\section{Date of task accomplishment}

April 17,1998 (final review)

\section{Name of task}

Requirements Analysis

\section{Identification of task in the V\&V plan (i.e. heading reference) Section 5.3.1, Item 1.}

\section{Narrative description of any preconditions}

The requirements document needs to be complete.

\section{Narrative description of any important environmental influences}

None.

\section{Narrative description of any other influences that affected task performance}

The requirements document author was unfamiliar with writing software requirements. Because of the concurrency between both requirements review and analysis, changes in the draft requirements document unavoidably had a ripple effect on requirements analysis.

\section{Narrative description of task}

1) Identify individual requirements

2) Allocate individual requirements as technical, operational, documentary, or hardware-specific.'

\section{Narrative summary of task results (acceptable or not acceptable)}

Acceptable. The requirements shifted as it became clear that NUFT did not perform some of the functions or actions called out. However, none of the changes conflicted with the objectives of the VVP or the ISP. The requirements shifting was an indication of the complexity of the NUFT code. There were approximately six items that changed after detailed requirements analysis. Two had clear technical effects on the range of variables or functions provided by the code, and four were misstatements of operational properties.

\footnotetext{
'Some requirements could appear in more than one category, viz. technical requirement that also had to be covered in user manual.
} 


\section{Recommendations}

More up-front training and a little better coordination of requirements analysis and requirements document production would be helpful. 033-YMP-QP 3.2's failure to recognize test plans as separate from the V\&V plan is at odds with all standard views of V\&V, and caused a considerable delay in final issuance of the VVP. Normally, requirements analysis and test plan generation are line items called out in a V\&V plan, and hence requirements analyses and test plans are products of executing a V\&V plan, not part of the V\&V plan. We recommend that YMP utilize existing standards (e.g. ANS 10.4, IEEE 1012, IEEE 828, IEEE 1042, IEEE 830, IEEE 829, IEEE 1074, or the ISO 9000 suite of standards, or the SEI capability maturity model). There is certainly no dearth of standards. Although it is difficult to predict at this time, NRC highlevel waste management may come down somewhere between 10 CFR 50 reactor regulation and 10 CFR 70 fuel processing plant regulation. The NRC has endorsed the IEEE standards mentioned for the development of safety related real time systems, and the NRC as whole prefers to endorse existing consensus standards rather than to maintain a singular approach that diverges from existing practice.

\section{Author Signature}

Date 


\section{Appendix 2 \\ Task Report \\ Test Plan Generation}

\section{Name(s) of task participant(s)}

Gary Preckshot, Gary Johnson, Ron Shaffer, Ken Lee

\section{Date of task accomplishment}

April 17, 1998 (final)

\section{Name of task}

Test plan generation

\section{Identification of task in the V\&V plan (i.e. heading reference)} Section 5.3.1, Item 2

\section{Narrative description of any preconditions}

The requirements analysis task must be completed.

\section{Narrative description of any important environmental influences}

None.

\section{Narrative description of any other influences that affected task performance}

The four subtasks ${ }^{2}$ in test plan generation were clear, but there was some question as to which requirements were being demonstrated by testing or observation. The pre-existence of an automated testing facility that functions in conjunction with software configuration management considerably speeded up the writing of the test plan.

There was an initial mismatch between test case descriptions and individual technical requirements. This required several meetings with domain experts to resolve. A document from Ken Lee is included in the VVP and details the specific test cases and identifies the functions and variable ranges tested. Addendum 1 to this task report summarizes the range of parameter coverage achieved by these test cases.

The test plan and the requirements document were developed concurrently. This required extra effort to coordinate the two documents and increased the potential that mismatches would exist between the documents. The final test plan was reviewed against the final RD to control this risk.

The test plan was prepared in accordance with a draft of Revision 4 to QP 3.2 with the expectation that that version would be in force at the time testing was completed. After the test plan was completed and testing was in progress, review of QP 3.2 identified an additional requirement for the use of test cases that were developed independently from the code developer. The test cases wee reviewed to confirm that independence exists. The results of this review are included as Addendum 2 to this task report.

\footnotetext{
${ }^{2}$ See Section 8 of this task report.
} 


\section{Narrative description of task}

1) Devise a plan for automated testing

2) Select test cases

3) Make a checklist for tester observations

4) Make a checklist for documentation reviewers

\section{Narrative summary of task results (acceptable or not acceptable)}

An acceptable test plan, test cases, and checklists were achieved. Test cases were selected by Ken Lee, a YMP hydrologist who is a domain expert in the NUFT application area. The specific test cases are identified in the test plan.

The requirements document identified the following acceptance criteria for automatic test cases

"For test problems NUFT results will satisfy at least one of the following three criteria:

(1) Parameter values will be within $5 \%$ of qualified data (analytically obtained parameter values or other qualificd parameter values).

(2) Parameter values will be within $5 \%$ of the normalized distance to the qualified time-history curve.

(3) Parameter values will be within $5 \%$ of the parameter variation from qualified data normalized to the parameter data range."

These acceptance criteria were selected by the hydrologists to ensure that errors introduced by NUFT are very small compared to input parameter and modeling uncertainties. These are commonly accepted criteria for other hydrological codes. Furthermore, variations of this order are typically not discernible on the graphical outputs used to interpret the results of NUFT analyses.

Configuration identification of test cases is given in the automated testing task report. The correspondence of test cases with functional requirements is shown in Table 2 of Section 8 of the V\&V plan. Two appendices (to the VVP) contain information from Ken Lee on mapping of test cases to functional requirements. Some of the test cases are not independent of the code developer, as required by 033-YMPQP 3.2. The test cases were reviewed for independence by Ken Lee and his appraisal is attached as addendum 1 to this task report. Checklists for tester observations and documentation review are Tables 3 and 4 , respectively.

\section{Recommendations}

Where testing plays so large a role in the acceptability of a technical software product, domain experts should be involved early and be thoroughly briefed on determining a documented relationship between test cases and identifiable functional requirements.

\section{Author Signature}

Date 


\section{Addendum 1}

\section{Range of NUFT Test Problems}

\section{Kenrick Lee}

Range of Primary Variables for NUFT Test Problems
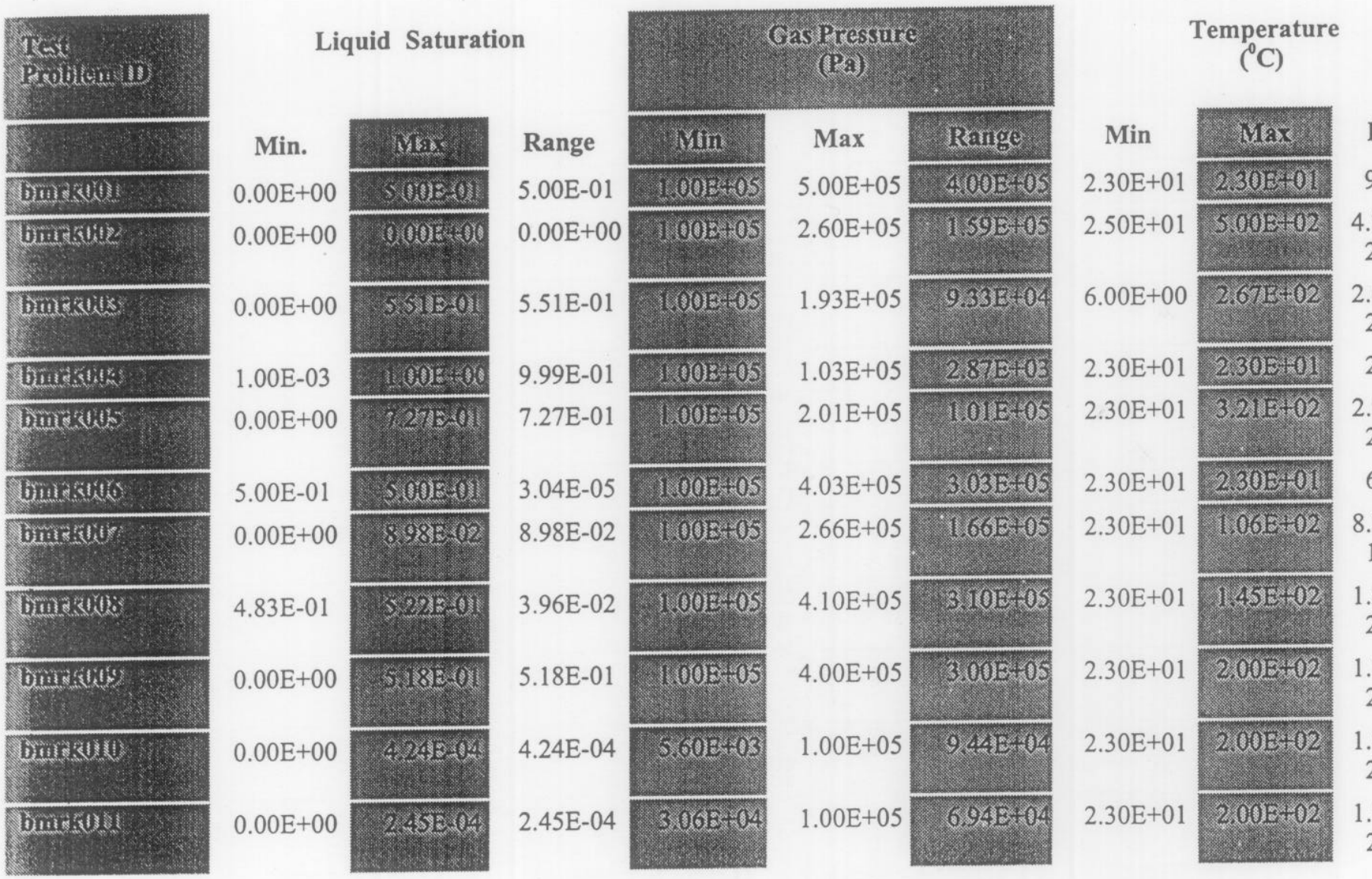

\begin{tabular}{|c|c|c|c|}
\hline Range & Min & Max & Range \\
\hline $5.00 \mathrm{E}-01$ & 1.0008405 & $5.00 \mathrm{E}+05$ & $4.00 \mathrm{E}+05$ \\
\hline $0.00 \mathrm{E}+00$ & $2.0012 \cdot 05$ & $2.60 \mathrm{E}+05$ & $159 \mathrm{E} \cdot 05$ \\
\hline $5.51 \mathrm{E}-01$ & $1100 \mathrm{E}+0$ & $1.93 \mathrm{E}+05$ & $9.33 \mathrm{E}$ \\
\hline $9.99 \mathrm{E}-01$ & $1.0028 \div 05$ & $1.03 E+05$ & $287 \mathrm{~B}+03$ \\
\hline $7.27 \mathrm{E}-01$ & $1.00 \mathrm{E}+1$ & $2.01 \mathrm{E}+05$ & $101 E+05$ \\
\hline 3.04E-05 & $1.00 \mathrm{E} \cdot 05$ & $4.03 E+05$ & $3.03 \mathrm{E}+05$ \\
\hline 8.98E-02 & $1.00 E+05$ & $2.66 \mathrm{E}+05$ & $166 \mathrm{E}+05$ \\
\hline $3.96 \mathrm{E}-02$ & $1.00 \mathrm{E}+05$ & $4.10 \mathrm{E}+05$ & $3.10 \mathrm{E} t 05$ \\
\hline $5.18 \mathrm{E}-01$ & $100 \mathrm{E}+05$ & $4.00 \mathrm{E}+05$ & 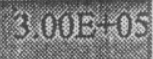 \\
\hline 4.24E-04 & $5.60 \mathrm{E}+0$ & $1.00 \mathrm{E}+05$ & 0 \\
\hline 2.45E-04 & 3.061 & $1.00 \mathrm{E}+05$ & $6.94 \mathrm{E}$ \\
\hline
\end{tabular}

\begin{tabular}{|c|c|c|}
\hline Min & Max & Range \\
\hline $30 \mathrm{E}+01$ & $2.30 E+01$ & $9.96 \mathrm{E}-$ \\
\hline $50 \mathrm{E}+01$ & $5.00 \mathrm{E}+102$ & $\begin{array}{l}4.75 \mathrm{E}+0 \\
2\end{array}$ \\
\hline $6.00 \mathrm{E}+00$ & $2.67 E+02$ & $\begin{array}{l}2.61 \mathrm{E}+0 \\
2\end{array}$ \\
\hline 2.30E+01 & $2.305+01$ & $2.71 \mathrm{E}-($ \\
\hline $2.30 \mathrm{E}+01$ & $3.21 \mathrm{E}+02$ & $\begin{array}{c}2.98 \mathrm{E}+0 \\
2\end{array}$ \\
\hline $2.30 \mathrm{E}+01$ & $2.30 \mathrm{E}+01$ & $6.05 \mathrm{E}-($ \\
\hline $2.30 \mathrm{E}+01$ & $1.06 \mathrm{E}+02$ & $\begin{array}{c}8.33 \mathrm{E}+0 \\
1\end{array}$ \\
\hline $2.30 \mathrm{E}+01$ & $45 E+02$ & $\begin{array}{c}1.22 \mathrm{E}+0 \\
2\end{array}$ \\
\hline $2.30 \mathrm{E}+01$ & $2.00 \mathrm{E}+02$ & $\begin{array}{l}1.77 \mathrm{E}+0 \\
2\end{array}$ \\
\hline $2.30 \mathrm{E}+01$ & $2.00 \mathrm{E}+02$ & $\begin{array}{l}1.77 \mathrm{E}+0 \\
2\end{array}$ \\
\hline $2.30 \mathrm{E}+01$ & $2.00 \mathrm{E}+02$ & $\begin{array}{c}1.77 \mathrm{E}+0 \\
2\end{array}$ \\
\hline
\end{tabular}

\begin{tabular}{|c|}
\hline Min \\
\hline $0.00 \mathrm{E}+00$ \\
\hline $0.00 \mathrm{E}+00$ \\
\hline $0.00 \mathrm{E}+00$ \\
\hline $1.71 \mathrm{E}-02$ \\
\hline $0.00 \mathrm{E}+00$ \\
\hline $4.34 \mathrm{E}-03$ \\
\hline $0.00 \mathrm{E}+00$ \\
\hline $1.75 \mathrm{E}-02$ \\
\hline $0.00 \mathrm{E}+00$ \\
\hline $0.00 \mathrm{E}+00$ \\
\hline $0.00 \mathrm{E}+00$ \\
\hline
\end{tabular}

\begin{tabular}{|c|c|}
\hline Max & Range \\
\hline $1.76 \mathrm{E}-02$ & $1.76 \mathrm{E}=02$ \\
\hline $0.00 \mathrm{E}+00$ & 10, \\
\hline $0 \mathrm{E}+00$ & $10.018 \times 10$ \\
\hline $6 \mathrm{E}-02$ & 4.961404 \\
\hline $00 \mathrm{E}+00$ & $1000 \mathrm{E}, 00$ \\
\hline $76 \mathrm{E}-02$ & 1.332402 \\
\hline $0 \mathrm{E}-01$ & 3.600 .01 \\
\hline $0 \mathrm{E}+00$ & $983 \mathrm{E}$ \\
\hline $0 \mathrm{E}+00$ & $1600 \mathrm{E}-20$ \\
\hline $0 \mathrm{E}+00$ & $0012+4$ \\
\hline $00 \mathrm{E}-01$ & $50001 \% 0$ \\
\hline
\end{tabular}




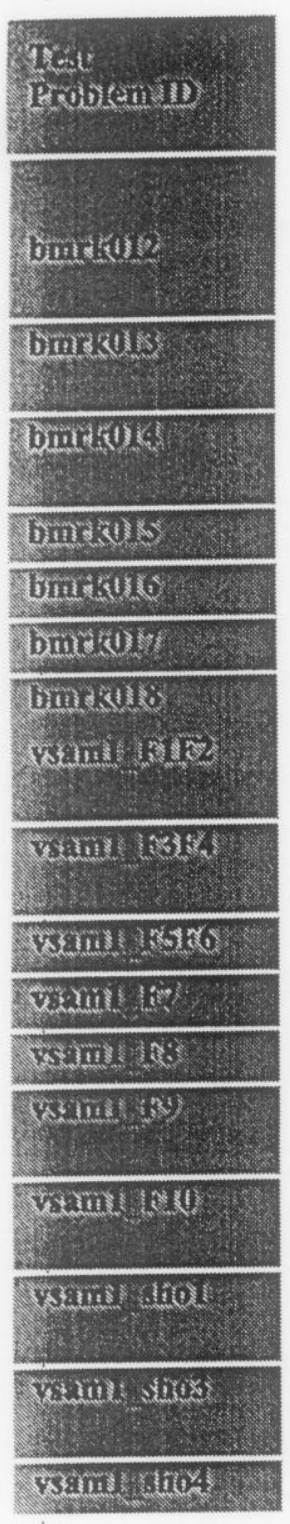

Liquid Saturation

\begin{tabular}{|c|c|}
\hline Min. & Mes \\
\hline $00 \mathrm{E}+00$ & $5011 \mathrm{E}$ \\
\hline & \\
\hline & $5.60 \mathrm{E}$ \\
\hline $0 \mathrm{E}-02$ & $500 \mathrm{E}-0$ \\
\hline $32 \mathrm{E}-04$ & $9.60 \mathrm{E}-0$ \\
\hline 0 E- 04 & $9.901 \mathrm{E} 0$ \\
\hline $00 \mathrm{E}+00$ & $5000 \mathrm{e}$ \\
\hline $0.00 \mathrm{E}+00$ & 10008 \\
\hline $00 \mathrm{E}+00$ & $100 \mathrm{E}$ \\
\hline $0.00 \mathrm{E}+00$ & $1000 \mathrm{E}+0$ \\
\hline $9.97 \mathrm{E}-01$ & $100 \mathrm{E}+4$ \\
\hline $9.94 \mathrm{E}-01$ & $100 \mathrm{EE}$ \\
\hline $0.00 \mathrm{E}+00$ & $00 \mathrm{E}$ \\
\hline $0.00 \mathrm{E}+00$ & 9.898 \\
\hline $00 \mathrm{E}+00$ & \\
\hline 49E-01 & 1 \\
\hline & \\
\hline
\end{tabular}

Cras Pressure (Pa)

\begin{tabular}{|c|c|}
\hline Max & Range \\
\hline $0 \mathrm{E}+05$ & $9.72 \mathrm{E}$ \\
\hline $.01 \mathrm{E}+05$ & $9.82 \mathrm{E}+$ \\
\hline $3 E+05$ & $8.25 \mathrm{E} \div 0$ \\
\hline $.00 \mathrm{E}+05$ & $1.76 E+04$ \\
\hline $.01 E+05$ & $761 \mathrm{E}-0.04$ \\
\hline $.00 \mathrm{E}+05$ & $4.00 \mathrm{E}=05$ \\
\hline $.00 \mathrm{E}+05$ & $400 \mathrm{E}$ \\
\hline $.00 \mathrm{E}+06$ & $9.00 \mathrm{E}$ \\
\hline $.90 \mathrm{E}+06$ & $9.80 E=06$ \\
\hline $1.00 \mathrm{E}+07$ & $9.00 \mathrm{E}+06$ \\
\hline $1.03 \mathrm{E}+07$ & $1.025+02$ \\
\hline $1.00 \mathrm{E}+07$ & $1,46 \mathrm{E}+06$ \\
\hline $2.97 \mathrm{E}+06$ & $287 \mathrm{E}$ \\
\hline $4.00 \mathrm{E}+06$ & $\rightarrow \mathrm{na}$ \\
\hline $9.15 \mathrm{E}+06$ & $6.64 \mathrm{E}+06$ \\
\hline $4.50 \mathrm{E}+06$ & $3.78 \mathrm{E}$ \\
\hline $4.50 \mathrm{E}+06$ & $3.78 \mathrm{E}+06$ \\
\hline
\end{tabular}

Temperature ( $\mathrm{C})$

\begin{tabular}{|c|c|c|c|c|c|}
\hline Min & Max & Range & Min & Max & Rainge \\
\hline $2.30 \mathrm{E}+01$ & $2.00 E+02$ & $\begin{array}{l}1.77 \mathrm{E}+0 \\
2\end{array}$ & $1.76 \mathrm{E}-02$ & $1.00 \mathrm{E}+00$ & $98822=01$ \\
\hline $2.30 \mathrm{E}+01$ & $2.00 \mathrm{E}+02$ & $\begin{array}{l}1.77 \mathrm{E}+0 \\
2\end{array}$ & $0.00 \mathrm{E} t$ & $1.00 \mathrm{E}+00$ & $100 \mathrm{E} \times 00$ \\
\hline $2.30 \mathrm{E}+01$ & $2.67 \mathrm{E}+02$ & $\begin{array}{l}2.44 \mathrm{E}+0 \\
2\end{array}$ & $0.00 \mathrm{E}+00$ & $1.00 \mathrm{E}+00$ & $1000 \mathrm{E}-00$ \\
\hline $2.30 \mathrm{E}+01$ & $2.30 \mathrm{E}+01$ & $1.49 \mathrm{E}-03$ & $1.76 \mathrm{E} .02$ & $2.14 \mathrm{E}-02$ & 3.8210 .02 \\
\hline $2.30 \mathrm{E}+01$ & $2.30 \mathrm{E}+01$ & $7.86 \mathrm{E}-03$ & $1,75 \mathrm{E}-02$ & 7.34E-02 & $5.6003 \times 102$ \\
\hline $2.30 \mathrm{E}+01$ & $2.308+01$ & $1.44 \mathrm{E}-02$ & $3.49 \mathrm{E}-03$ & $1.76 \mathrm{E}-02$ & 1416.02 \\
\hline $2.30 \mathrm{E}+01$ & $2.30 \mathrm{E}+01$ & $9.96 \mathrm{E}-03$ & $0.00 \mathrm{E}+00$ & $1.76 \mathrm{E}-02$ & $1060: 02$ \\
\hline $2.00 \mathrm{E}+01$ & $1,70 \mathrm{~s}+02$ & $\begin{array}{c}1.50 \mathrm{E}+0 \\
2\end{array}$ & $0.00 \mathrm{E}+00$ & $1.00 \mathrm{E}+00$ & $1.0033+00$ \\
\hline $9.95 \mathrm{E}+01$ & $3.10 \mathrm{E}+02$ & $\begin{array}{c}2.11 \mathrm{E}+0 \\
2\end{array}$ & $0.00 E+00$ & $9.95 \mathrm{E}-01$ & $9.958 \times 11$ \\
\hline $9.99 \mathrm{E}+01$ & $100 \mathrm{E}+02$ & $4.59 \mathrm{E}-01$ & $0.00 \mathrm{E}+00$ & $3.14 \mathrm{E}-02$ & $3 \times 282=42$ \\
\hline $2.00 \mathrm{E}+01$ & $201 E+01$ & $1.25 \mathrm{E}-01$ & $0.00 \mathrm{E}+00$ & 4.67E-03 & 48076 \\
\hline $3.00 \mathrm{E}+02$ & $3.00 \mathrm{E}+02$ & 4.42E-01 & $0.00 E+00$ & $1.00 \mathrm{E}+00$ & $0100 \mathrm{E}+00$ \\
\hline $9.00 \mathrm{E}+01$ & $3.83 \mathrm{E}+02$ & $\begin{array}{c}2.93 \mathrm{E}+0 \\
2\end{array}$ & $5.93 \mathrm{E}-01$ & $9.72 \mathrm{E}-01$ & 3.798 .01 \\
\hline $2.11 \mathrm{E}+02$ & $2.80 E+02$ & $\begin{array}{c}6.94 \mathrm{E}+0 \\
1\end{array}$ & $1.00 \mathrm{E}+00$ & $1.00 \mathrm{E}+00$ & $0.00 \mathrm{E}+00$ \\
\hline $1.00 \mathrm{E}+02$ & $2.83 E+02$ & $\begin{array}{l}1.83 \mathrm{E}+0 \\
2\end{array}$ & $0.00 \mathrm{E}+00$ & $9.10 \mathrm{E}-01$ & $9808-01$ \\
\hline $1.66 \mathrm{E}+02$ & $2.50 E+02$ & $\begin{array}{c}8.36 \mathrm{E}+0 \\
1\end{array}$ & $8.25 \mathrm{E}-01$ & $1.00 \mathrm{E}+00$ & 7650 \\
\hline $1.66 \mathrm{E}+02$ & $2.50 \mathrm{E}+02$ & $8.36 \mathrm{E}+0$ & $8.25 \mathrm{E}-01$ & $1.00 \mathrm{E}+00$ & 11.352601 \\
\hline
\end{tabular}




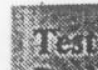

troblem in

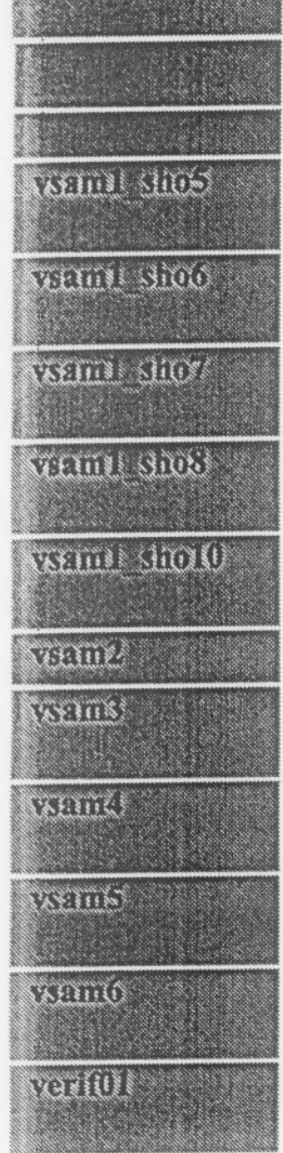

Liquid Saturation

Min.

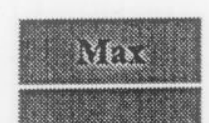

2.49E-01

$2.28 \mathrm{E}-01$

2.28E-01

$2.28 \mathrm{E}-01$

$5.00 \mathrm{E}-01$

$0.00 \mathrm{E}+00$

$0.00 \mathrm{E}+00$

3.94E-01

$6.51 \mathrm{E}-01$

$0.00 \mathrm{E}+00$

$0.00 \mathrm{E}+00$

N/A

$5006-01$

Range

2.51E-01

5.005 .01

500 EEO

2.72E-01

$2.72 \mathrm{E}-01$

$5.00 \mathrm{e} .01$

2.72E-01

9014501

$0.100 \mathrm{E}+00$

$9.97 \mathrm{E} .0$

(1., $1.00 \mathrm{E}+00$

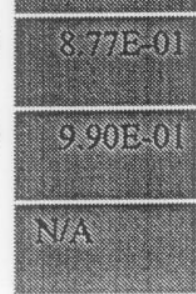

8.77E-01

$9.90 \mathrm{E}-01$

N/A
Gas Pressure (Pa)

\begin{tabular}{|l|l|}
\hline Max \\
\hline
\end{tabular}

$4 . 0 4 \mathrm { E } - 0 1 \longdiv { 4 . 5 0 \mathrm { E } + 0 6 }$

$1 . 0 0 \mathrm { E } + 0 0 \longdiv { 1 . 0 0 0 0 + 0 5 }$

$6 . 0 3 \mathrm { E } - 0 1 \longdiv { 1 . 0 0 \mathrm { E } + 0 5 }$

$3 . 4 9 \mathrm { E } - 0 1 \longdiv { 4 3 2 2 \mathrm { E } + 0 6 }$
Temperature (C)

\begin{tabular}{|c|c|c|}
\hline \multirow[t]{2}{*}{ Min } & Max & Range \\
\hline & & 1 \\
\hline $.66 \mathrm{E}+02$ & $2.50 E+02$ & $\begin{array}{c}8.36 \mathrm{E}+0 \\
1\end{array}$ \\
\hline $5.38 \mathrm{E}+01$ & $2.50 \mathrm{E}$ & $\begin{array}{c}1.96 \mathrm{E}+0 \\
2\end{array}$ \\
\hline $5.38 \mathrm{E}+01$ & $2.50 \mathrm{E}+02$ & $\begin{array}{c}1.96 \mathrm{E}+0 \\
2\end{array}$ \\
\hline $5.38 E+01$ & $2.50 E$ & $\begin{array}{c}1.96 \mathrm{E}+0 \\
2\end{array}$ \\
\hline $2.50 \mathrm{E}+02$ & $2.83 \mathrm{Et}$ & $\begin{array}{c}3.26 \mathrm{E}+0 \\
1\end{array}$ \\
\hline $2.00 \mathrm{E}+01$ & $200 \mathrm{E}+01$ & $3.05 \mathrm{E}-0$ \\
\hline $2.00 \mathrm{E}+01$ & $2.00 \mathrm{E}+$ & $\begin{array}{l}0.00 \mathrm{E}+0 \\
0\end{array}$ \\
\hline $2.55 \mathrm{E}+02$ & $3.00 \mathrm{E}+02$ & $\begin{array}{c}4.51 \mathrm{E}+0 \\
1\end{array}$ \\
\hline $2.60 \mathrm{E}+01$ & $1.53 E+02$ & $\begin{array}{l}1.27 \mathrm{E}+0 \\
2\end{array}$ \\
\hline $7.00 \mathrm{E}+01$ & $127 \mathrm{E}+02$ & $\begin{array}{c}5.66 \mathrm{E}+0 \\
1\end{array}$ \\
\hline $.00 \mathrm{E}+01$ & $1.00 E+02$ & $\begin{array}{c}8.00 \mathrm{E}+0 \\
1\end{array}$ \\
\hline
\end{tabular}

Water Mass ifraction in Ca:

\begin{tabular}{|c|c|c|}
\hline Min & Max & Range \\
\hline $8.25 \mathrm{E} .01$ & $1.00 \mathrm{E}+00$ & $1,750.01$ \\
\hline $3.54 \mathrm{E} .02$ & $8.26 \mathrm{E}-01$ & $7.90 \mathrm{E} \cdot 31$ \\
\hline $3.54 \mathrm{E} \cdot 02$ & $8.26 \mathrm{E}-01$ & 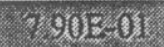 \\
\hline $3.54 \mathrm{E} \cdot 02$ & $8.26 \mathrm{E}-01$ & S OUEY \\
\hline $6.26 \mathrm{E}=01$ & $8.25 \mathrm{E}-01$ & $200 \mathrm{E}-01$ \\
\hline $0.00 \mathrm{E}+00$ & $1.47 \mathrm{E}-02$ & 1 - $15 \cdot 02$ \\
\hline $1.47 \mathrm{E}-02$ & $1.47 \mathrm{E}-02$ & $9 \times 10 \mathrm{E}=06$ \\
\hline $0.00 \mathrm{E}+00$ & $1.00 \mathrm{E}+00$ & $13001 \% \div 0$ \\
\hline $2.12 \mathrm{E}-02$ & $1.00 \mathrm{E}+00$ & $9.791 \mathrm{~B}, 01$ \\
\hline $195 \mathrm{E}-01$ & $1.00 \mathrm{E}+00$ & 835180 \\
\hline N/A & N/A & 8 \\
\hline
\end{tabular}

Range of Primary Variables Over all Test Problems 


\begin{tabular}{|c|c|c|c|c|c|c|c|c|c|c|c|}
\hline \multirow{2}{*}{\multicolumn{3}{|c|}{ Liquid Saturation }} & \multirow{2}{*}{\multicolumn{2}{|c|}{$\begin{array}{c}\text { Gas Pressure } \\
\left(P_{2}\right)\end{array}$}} & & \multirow{2}{*}{\multicolumn{2}{|c|}{$\begin{array}{c}\text { Temperature } \\
\left({ }^{\circ} \mathrm{C}\right)\end{array}$}} & \multicolumn{4}{|c|}{ 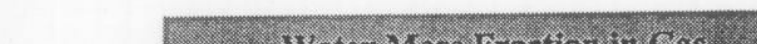 } \\
\hline & & & & & & & & & Water & Mass Fracti & in Gas: \\
\hline Min. & Max & Range & Min & $\operatorname{Max}$ & Range: & Min & Max & Range & Min & $\operatorname{Max}$ & Range \\
\hline $.00 \mathrm{E}+00$ & $100 \mathrm{E}+00$ & $1.00 \mathrm{E}+00$ & $2.671+03$ & $1.03 \mathrm{E}+07$ & $1.03 E+07$ & $6.00 \mathrm{E}+00$ & $5.00 \mathrm{~B}+02$ & $4.94 \mathrm{E}+02$ & $0.00 E+00$ & $1.00 \mathrm{E}+00$ & $1.00 \mathrm{E}+00$ \\
\hline
\end{tabular}




\section{Addendum 2}

\section{Independence of Test Cases \\ Kenrick Lee}

Of the 25 test cases that constitute the NUFT test case suite, 8 were selected or developed by hydrologists who made no contribution to the development of the code. These 8 test cases are bmrk018, vsam 1 through vsam6, and verif01. The remaining 17 cases, bmrk001 through bmrk017, were selected and prepared by John Nitao, the developer of NUFT.

The vsam test cases, vsaml through vsam6, are one- and two-dimensional problems taken from the TOUGH manual (Pruess, 1985). These problems were used in testing the TOUGH code, and later, in the qualification of VTOUGH. Like the bmrk problems, the vsam problems examine many of the thermohydrologic processes that are important to nuclear waste disposal at the proposed repository site in Yucca Mountain. Vsam2 through vsam6 address more practical problems that examine multiple interacting processes, in $1 \mathrm{D}$ and $2 \mathrm{D}$.

Bmrk018 and verif0l were prepared by Kenrick Lee, a hydrologist at LLNL. Bmrk018 tests the code's restart capability, and verif01 tests the code's ability to accurately solve three-dimensional problems.

The test cases prepared by NUFT's developer are basic 1D tests that examine code performance in modcling spccific physical processes that are important to thermo-hydrologic fluid flow in the subsurface. Typical test cases would have been selected by any competent hydrologist. 


\section{Appendix 3}

Task Report

Automated Testing

\section{Name(s) of task participant(s)}

Lynn Lewis

Al Leibee

\section{Date of task accomplishment}

April 29, 1998

\section{Name of task}

Testing

\section{Identification of task in the V\&V plan (i.e. heading reference)} Section 5.6.1, Items 1 and 2.

\section{Narrative description of any preconditions}

1) Source code must be checked in to software configuration management system

2) Test plan must be complete

3) Test cascs must be identificd and programmed

\section{Narrative description of any important environmental} influences

Testing is performed in an office environment on target platforms. Testing was performed using a guest account on a HP 9000/780 machine belonging to LLNL's B-Division. CPU time had to be shared with B-Division users and the B-Division users had the ability to lower the priority of the NUFT validation run. This is thought to have significantly lengthened the time required for completion of the validation run.

\section{Narrative description of any other influences that affected task performance}

None.

8. Narrative description of task 


\section{Narrative summary of task results (acceptable or not acceptable)}

The test script automatically evaluates the acceptability of the results from executing the test problems.

Testing, static analysis, dynamic analysis, and test coverage analysis identified a number of anomalies. The anomalies were reviewed and found to be acceptable. Copies of the anomaly report and evaluation are contained in Appendix 8A.

The observation checklist from the V\&V Plan was acceptably completed. The completed checklist is included in Appendix 8C.

All testing records are contained on magnetic media in records package LLYMP9804051. Sections 9.3 and 9.4 provide an index to testing records on the magnetic media.

\section{Recommendations}

The electronic configuration management system should become part of the LLNL YMP records management system so that it may be utilized for maintaining QA records of test activities.

The testers should have a dedicated HP workstation. Testing went significantly slower than anticipated because of the need to share CPU time with other users and because of the ability of the host organization to run at higher priority than the validation testing.

\section{Author Signature}

Date 


\title{
Appendix 4 \\ Task Report \\ Documentation Review
}

\author{
1. Name(s) of task participant(s) \\ Charles Carrigan \\ Gary Johnson \\ Mike Fernandez
}

\section{Date of task accomplishment}

April 30, 1998

\section{Name of task}

Documentation and release note review.

4. Identification of task in the V\&V plan (i.e. heading reference) Section 5.6.1, Item 3 .

\section{Narrative description of any preconditions}

1) Availability of documentation and release notes.

2) Completion of test plan.

\section{Narrative description of any important environmental influences}

None.

\section{Narrative description of any other influences that affected task performance}

None.

\section{Narrative description of task}

Charles Carrigan reviewed the NUFT documentation against the QP 3.2 acceptance criteria as documented in the QP 3.2 checklist.

Mike Fernandez reviewed the NUFT user's manual and theory manual against the subject coverage checklist from the test plan.

Gary Johnson reviewed the NUFT release notes against subject coverage checklist from the test plan. 
11. Author Signature

Date 


\title{
Appendix 5
}

Task Report

Configuration audit

\section{Name(s) of task participant(s)}

\author{
Al Leibee \\ Ken Lee \\ Lynn Lewis \\ John Nitao \\ Gary Johnson
}

\section{Date of task accomplishment}

April 30, 1998

\section{Name of task}

Configuration Audit.

\section{Identification of task in the V\&V plan (i.e. heading reference)}

Section 5.7.1, Item 1. The objective of the Release Physical Audit Procedure is to provide an independent evaluation of a Release to verify that the software and its documentation are internally consistent and are ready for delivery.

\section{Narrative description of any preconditions}

1) An installation package must exist.

2) The software configuration management system must be up-to-date.

3) A delivery specification must exist.

\section{Narrative description of any important environmental influences}

None.

\section{Narrative description of any other influences that affected task performance}

None.

\section{Narrative description of task}

1. Examined test documentation to confirm: 
Ensured that all test cases are present.

Checked a sample of files to ensure that tests cover requirements and that actual results are within tolerance of expected results.

3. Examined Release Bill-of-Materials to confirm:

All configuration items are accounted for.

Revision numbers of items generated or

modified for this Release are correct.

All tools are accounted for.

Revision numbers are correct.

4. Examined release identification:

Checked a sample of test output files to ensure that correct Release identificr is displayed.

5. Examined build logs:

Release build log:

Checked that correct compile-link options

were used.

Checked that all warning messages are

explicable and acceptable.

Instrumented Release build log: Checked that correct compile-link options were used.

Checked that all warning messages are

explicable and acceptable.

6. Distribution package:

uuencoded distribution file

Installation script

Installation instructions

Followed installation instructions to install distribution.

Checked that all components present.

Ran sample test problem and verify results.

7. User documentation:

Checked user documentation for completeness and correct labeling.

8. Repository:

Checked that the Repository and the Release configuration items are consistent. This can be done by performing a nuft_co which causes a Modification Series to be created based on the Release's Bill-of-Materials.

\section{Narrative summary of task results (acceptable or not acceptable)}

Examined test documentation to confirm:

Lint log:

Insight test run log:
Static analysis exceptions were identified and documented in a Software Problem / Deficiency Report and dispositions as accept-as-is. Appendix 8A contains copies of the problem report.

One dynamic analysis exception was identified and documented in a Software Problem / Deficiency Report and dispositions as accept-as-is. Appendix 8A contains copies of the problem report. 
Insight test coverage report: Coverage analysis was found to be very low. This was identified and documented in a Software Problem / Deficiency Report and dispositions as accept-as-is. Appendix 8A contains copies of the problem report.

Test differences log: Test anomalies were identified for 11 points in total from tests vsam 5 and vsam6. These were documented in a Software Problem / Deficiency Report and dispositions as accept-as-is. Appendix 8A contains copies of the problem report.

Examined test case files. All input files, expected output files, actual output files and test cases are present.

Examined Release Bill-of-Materials. All configuration items are accounted for. The revision numbers of items for this Release are correct. All tools are accounted for. All tool revision numbers are correct.

Examined release identification. A sample of test output files was checked and found to display the correct Release identifier.

Examined release build log. Correct compile-link options were used. All warning messages are explicable and acceptable.

Examined instrumented Release build log. Correct compile-link options were used. All warning messages are explicable and acceptable.

Distribution package contains uuencoded distribution file installation script installation instructions

Followed installation instructions to install distribution. All components were present. Sample test problem successfully executed.

User documentation is completeness and correctly labeled [HOLD].

Repository and the Release configuration items are consistent

\section{Recommendations}

None.

\section{Author Signature}

Date 


\section{Appendix6 \\ Task Report \\ Installation at Livermore}

\section{Name(s) of task participant(s) \\ DavidGutierrez}

\section{Date of task accomplishment}

April 26, 1998

\section{Name of task}

Installation test on target platform in Livermore.

\section{Identification of task in the V\&V plan (i.e. heading reference)}

Section 5.7.1, Item 2, done on target platform in Livermore.

\section{Narrative description of any preconditions}

1) A released installation package must be available

2) A target platform at the YMP site in Livermore must be available

3) An independent software engineer must be available in Livermore to perform and test the installation.

\section{Narrative description of any important environmental influences}

The test platform was a HP $712 / 60$ (PA-Risc 1.1) with 98 MB of memory running HP-UX Version 10.20, $\mathrm{X}$-windows Version X11R6, and Motif Version 1.2.

The software was installed into the directory identified into the release notes.

\section{Narrative description of any other influences that affected task performance}

None.

\section{Narrative description of task}

A copy of the NUFT installation package was obtained from email distribution (5 separate emails with enclosed attachments).

NUFT was installed using the following email instructions.

I. Receiving the NUFT Release Distribution

The NUFT Release Distribution is composed of the NUFT Executable Distribution and files for installing the NUFT Executable Distribution on your platform.

You will receive the NUFT Release Distribution in four parts via four separate e-mails. Each part contained within the e-mail is delineated by a line containing "Begin <part>" and a line containing "End <part $>$ " where <part> is the name of the part. After saving each e-mail into a file, you should delete all lines preceding Begin $<$ part $>$, 
the Begin <part> line, the End <part> line, and all lines following the End < part $>$ line.

The four e-mails are:

E-mail for the README part

The Subject field of this e-mail is: NUFT Release 2.0h README

This e-mail contains the NUFT Release Distribution README file.

The README file contains the instructions for installing the NUFT Distribution on your platform. It also contains a disposition of qualification test exceptions.

Save this e-mail as README.

E-mail for the INSTALL-SCRIPT part

The subject field of this e-mail is: NUFT Release $2.0 \mathrm{~h}$ INSTALL-SCRIPT

This e-mail contains the NUFT Release Distribution INSTALL-SCRIPT file.

INSTALL-SCRIPT is the C-shell script you will use to install the NUFT Executable

Distribution.

Save this e-mail as INSTALL-SCRIPT.

E-mail for the distuu part

The subject field of this e-mail is: NUFT Release $2.0 \mathrm{~h}$ dist.uu

This e-mail contains the NUFT Executable Distribution dist.uu file. dist.uu is a uuencoded file containing the NUFT Executable Distribution which contains the NUFT executable, ancillary files needed for NUFT execution, a sample input file, and user documentation files.

Save this e-mail as dist.uu

E-mail for the BOM-PROC part

The subject field of this e-mail is: NUFT Release 2.0h Bill-of-Materials

This e-mail contains a procedure for generating a bill-of-materials for the NUFT Release. The bill-of-materials lists the names and revision numbers of items used in the generation and qualification of NUFT Release 2.0h.

Save this e-mail as BOM-PROC.

II. Installing the NUFT Executable Distribution

After you have reccived all of the c-mails, follow the instructions in README to install NUFT.

III. Testing the NUFT Executable Distribution 
The directory in which you installed the NUFT Executable Distribution contains the NUFT input file instTEST.in and its associated output file instTEST.th.

1. cd to this directory.

2. Set the environment variable NUFTPATH to this directory.

3. Run the NUFT executable main with the input file:

main instTEST.in

main will produce an output file named instTEST.ex.

4. Compare instTEST.ex with instTEST.th:

diff instTEST.ex instTEST.th

The only difference should be in a line beginning with "\$RunDate".

\section{Narrative summary of task results (acceptable or not acceptable)}

The installation instructions are acceptable and everything worked as predicted

\section{0. . Recommendations}

None.

\section{Author Signature}

Date 


\section{Appendix 7 \\ Task Report \\ Management Activities}

\section{Name(s) of task participant(s)}

Gary L. Johnson, Gary Preckshot

\section{Date of task accomplishment}

April 27, 1998

\section{Name of task}

V\&V management.

\section{Identification of task in the V\&V plan (i.e. heading reference) Section 5.1.1.}

\section{Narrative description of any preconditions}

1) Tasking from upper management

2) Budget

6. Narrative description of any important environmental influences

None.

\section{Narrative description of any other influences that affected} task performance

The tight schedule impacted the effectiveness of V\&V. Use of personnel untrained in software method unavoidably impacted schedule. The schedule did not permit investigation of prior use of the product or a survey of developer QA or V\&V methods.

\section{Narrative description of task}

1) Production of the V\&V plan

2) Assignment of resources

3) Control and synchronization of schedule with other activities

4) Review to determine V\&V effectiveness

\section{Narrative summary of task results (acceptable or not acceptable)}

\subsection{Production of the V\&V plan}

An acceptable V\&V plan was produced, although the inclusion of requirements analysis and test plan is not customary. The plan is sufficient for the qualification of NUFT for non-critical (as defined by IEEE Std 1012-1986 and NRC practice) software. 


\subsection{Assignment of Resources}

This V\&V operation was resource-limited. Personnel resources were assigned at full capacity as tasks became available. Acceptable utilization of resources was achieved.

\subsection{Control and Synchronization of Schedule}

Maximum use of concurrency was made. This resulted in some necessity for rework because dependencies existed between concurrent tasks. This was an acceptable cost for accomplishing the V\&V task on schedule.

\subsection{Review of V\&V Effectiveness}

NUFT $2.0 \mathrm{~h}$ successfully completed testing to verify that the NUFT software is suitable for use by qualified professionals to understand and evaluate the effects of the planned Yucca Mountain Repository cross drift test.

The suitability of NUFT $2.0 \mathrm{~h}$ for other applications is unknown at this time for the following reasons:

1. Limited test coverage

2. Limited design information

3. Limited design process information

4. Limited documented operating experience data

Resolving these limitations for release $2.0 \mathrm{~h}$ was not possible given the schedule constraints.

This was acceptable performance for a first-time trial of the procedures detailed by 033-YMP-QP 3.2. A post-mortum review of this effort should be conducted to identify process improvements that should be incorporated into future revisions of QP 3.2.

\section{Recommendations}

1) 033-YMP-QP 3.2 should be modified and peer-reviewed under applicable YMP QA procedures by software professionals, including some experts from academia.

2) Training should be established for affected YMP personnel that prepares them to do V\&V correctly.

3) YMP Q $\Lambda$ procedures should be moved in the direction of 10 CFR 50 Appendix B QA procedures, including software QA, so that there is not a large transient when the YMP comes under the direct purview of the NRC, as described in 10 CFR Part 60.

\section{Author Signature}

Date 


\section{Appendix 8}

Handwritten Reviews can be found in Records Package

LLYMP9804051 